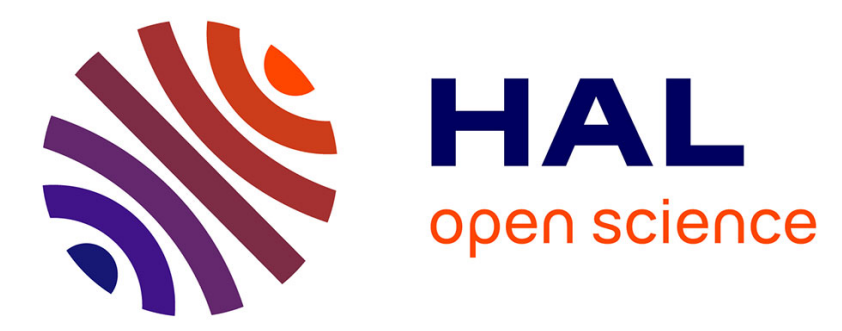

\title{
Pseudo-2-Fold Surface of the Al13Co4 Catalyst: Structure, Stability, and Hydrogen Adsorption
}

Corentin Chatelier, Yves Garreau, Alina Vlad, Julian Ledieu, Andrea Resta, Vincent Fournée, Marie-Cécile de Weerd, Alessandro Coati, Emilie Gaudry

\section{- To cite this version:}

Corentin Chatelier, Yves Garreau, Alina Vlad, Julian Ledieu, Andrea Resta, et al.. Pseudo-2-Fold Surface of the Al13Co4 Catalyst: Structure, Stability, and Hydrogen Adsorption. ACS Applied Materials \& Interfaces, 2020, 12 (35), pp.39787-39797. 10.1021/acsami.0c09702 . hal-03006464

\section{HAL Id: hal-03006464 https://hal.science/hal-03006464}

Submitted on 30 Nov 2020

HAL is a multi-disciplinary open access archive for the deposit and dissemination of scientific research documents, whether they are published or not. The documents may come from teaching and research institutions in France or abroad, or from public or private research centers.
L'archive ouverte pluridisciplinaire HAL, est destinée au dépôt et à la diffusion de documents scientifiques de niveau recherche, publiés ou non, émanant des établissements d'enseignement et de recherche français ou étrangers, des laboratoires publics ou privés. 


\title{
The pseudo-twofold surface of the $\mathrm{Al}_{13} \mathrm{Co}_{4}$ catalyst: structure, stability, and hydrogen adsorption
}

\author{
Corentin Chatelier ${ }^{1,2}$, Yves Garreau ${ }^{2,3}$, Alina Vlad ${ }^{2}$, Julian Ledieu ${ }^{1}$, Andrea Resta ${ }^{2}$, \\ Vincent Fournée ${ }^{1}$, Marie-Cécile de Weerd ${ }^{1}$, Alessandro Coati*,2 and Émilie Gaudry ${ }^{*, 1}$ \\ ${ }^{1}$ Université de Lorraine, CNRS, Institut Jean Lamour - UMR 7198, F-54011, Nancy, France \\ ${ }^{2}$ Synchrotron SOLEIL, L'Orme des Merisiers, Saint-Aubin, BP 48, F-91192 Gif-sur-Yvette Cedex, France \\ ${ }^{3}$ Université de Paris, CNRS, Matériaux et Phénomènes Quantiques - UMR 7162, Paris, France \\ E-mail: alessandro.coati@synchrotron-soleil.fr,emilie.gaudry@univ-lorraine.fr
}

\begin{abstract}
A few low order approximants to decagonal quasicrystals have been shown to provide excellent activity and selectivity for the hydrogenation of alkenes and alkynes. It is the case for the $\mathrm{Al}_{13} \mathrm{Co}_{4}$ compound, for which the catalytic properties of the pseudo-twofold orientation have been revealed to be among the best. A combination of surface science studies, including Surface X-Ray Diffraction, and calculations based on Density Functional Theory, is used here to derive an atomistic model for the pseudo-twofold $o-\mathrm{Al}_{13} \mathrm{Co}_{4}$ surface, whose faceted and columnar structure is found very similar to the one of the twofold surface of the $d$-Al-Ni-Co quasicrystal. Facets substantially stabilize the system, with energies in the range $1.19-1.31 \mathrm{~J} / \mathrm{m}^{2}$, i.e. much smaller than the ones of the pseudo-tenfold $\left(1.49-1.68 \mathrm{~J} / \mathrm{m}^{2}\right)$ and pseudo-twofold $\left(1.66 \mathrm{~J} / \mathrm{m}^{2}\right)$ surfaces. Faceting is also a main factor at the origin of the $\mathrm{Al}_{13} \mathrm{Co}_{4}$ catalytic performances, as illustrated by the comparison of the pseudo-tenfold, pseudotwofold and facet potential energy maps for hydrogen adsorption. This work gives insights towards the design of complex intermetallics catalysts through surface nanostructuration for optimized catalytic performances.
\end{abstract}

\section{Introduction}

Since their discovery, ${ }^{1}$ quasicrystals have raised substantial interest regarding their unique chemical and physical properties. Coincident structural long-range order and absence of translational symmetry lead to remarkable transport properties ${ }^{2-5}$ which are promising for several uses, such as, for example, the control of wave localization for photonic applications. ${ }^{6}$ Even so, most promising applications rely on their surfacerelated properties, like oxidation resistance, high hardness, low coefficient of friction, and more recently catalytic activity. ${ }^{2,7}$ All of these properties are ultimately related to the surface physics and chemistry at the atomic scale. Therefore, a detailed description of the surface structures is a prerequisite to understand how these surfaces interact with their environment.

High symmetry surfaces of quasicrystalline phases have been thoroughly investigated over the last years. Fivefold and tenfold surfaces generally present large flat terraces, corresponding to bulk truncations at specific atomic planes. ${ }^{8-11}$ Twofold surfaces were primarily considered as less stable. ${ }^{12-14}$ The former conclusion, drawn from the relative surface stabilities of icosahedral i-AlPdMn, appeared however to be not so clear, even non valid, for twofold surfaces of quasicrystals with different structures or/and compositions (i-AgInYb, ${ }^{15}$ i-AlPdRe, ${ }^{16}$ decagonal d-AlNiCo, ${ }^{17}$ d-AlCuCo $\left.{ }^{18}\right)$. In these studies, relative surface stabilities of different ori- entations were evaluated through the tendency to form facets, or through surface atomic densities, derived from the comparison of possible surface atomic arrangements with models built by bulk truncations. As far as we know, no validation has been achieved through precise surface energy calculations on these systems, due to the complexity and the non-periodic character of the structures.

Periodic approximant structures to quasicrystals represent a very useful approach to deepen our understanding of quasicrystalline phases. Because they exhibit atomic arrangements similar to those encountered in quasicrystals, in large crystal cells, they bridge the gap between periodic and aperiodic positional order. They have nicely contributed to unveil the structure and properties of a few quasicrystalline surfaces, through density functional theory calculations using periodic boundary conditions, such as the fivefold surface of i-AlPdMn ${ }^{19,20}$ or the tenfold surface of d-AlCoNi. ${ }^{21}$ They were crucial for the discovery of templated singleelement quasicrystalline thin film, ${ }^{22,23}$ or to demonstrate that specific local atomic arrangement, favorable for selective catalytic properties, naturally appear at surfaces with pentagonal symmetry. ${ }^{24-26}$

A few low order approximants to decagonal quasicrystals have been shown to provide excellent activity and selectivity for alkene and alkyne hydrogenation. ${ }^{27-30}$ It is the case for the $\mathrm{Al}_{13} \mathrm{TM}_{4}$ compounds ( $\mathrm{TM}=$ transition metal), for wich the site isolation has been 
identified as an important factor for the catalytic performances towards butadiene hydrogenation. ${ }^{30}$ Among them, the monoclinic $m$ - $\mathrm{Al}_{13} \mathrm{Fe}_{4}(010)$ was revealed as the most active model catalyst at room temperature, and the orthorhombic $o-\mathrm{Al}_{13} \mathrm{Co}_{4}(010)$ was determined as the most active one at higher temperature (110 ${ }^{\circ} \mathrm{C}$ ), while remaining $100 \%$ selective to butenes unlike $\mathrm{Al}_{13} \mathrm{Fe}_{4}(010)$. Regardless of temperature, the $o-$ $\mathrm{Al}_{13} \mathrm{Co}_{4}(010)$ pseudo-twofold surface was found much more active than the $\mathrm{o}-\mathrm{Al}_{13} \mathrm{Co}_{4}(100)$ pseudo-tenfold orientation. While the pseudo-tenfold surface has been extensively studied these last years, ${ }^{31-35}$ very few is known about the $o-\mathrm{Al}_{13} \mathrm{Co}_{4}(010)$ peudo-twofold surface structure and properties. On the basis of surface science techniques, including Surface X-Ray Diffraction (SXRD), combined with Density Functional Theory (DFT) calculations, we derive a model at the atomic scale for the $o-\mathrm{Al}_{13} \mathrm{Co}_{4}(010)$ faceted and columnar structure, analogous to the one of the twofold $\mathrm{d}$ Al-Ni-Co surface. Surface energy calculations identify the facets as a main factor for the stability of the $\mathrm{Al}_{13} \mathrm{Co}_{4}$ pseudo-twofold orientation, while potential energy maps for hydrogen adsorption suggest their role in the improved catalytic performances of $o-\mathrm{Al}_{13} \mathrm{Co}_{4}(010)$ towards hydrogenation reactions.

\section{Materials and Methods}

\section{$\mathrm{Al}_{13} \mathrm{Co}_{4}$ crystal structures}

So far, six phases from the $\mathrm{Al}_{13} \mathrm{Co}_{4}$ family were reported: ${ }^{36} \mathrm{Z}-\mathrm{Al}_{3} \mathrm{Co}, \mathrm{Y} 1-\mathrm{Al}_{13} \mathrm{Co}_{4}, \mathrm{Y} 2-\mathrm{Al}_{13} \mathrm{Co}_{4}, \quad m$ $\mathrm{Al}_{13} \mathrm{Co}_{4}, o-\mathrm{Al}_{13} \mathrm{Co}_{4}$, and $o^{\prime}-\mathrm{Al}_{13} \mathrm{Co}_{4}$, with slightly different structures. In this study, we used an orthorhombic crystal $\left(o-\mathrm{Al}_{13} \mathrm{Co}_{4}\right)$, whose structure belong to the $P m n 2_{1}$ space group (No. 31, Pearson symbol oP102) and whose crystal cell is defined with the following lattice parameters: $\mathrm{a}_{\mathrm{o}}=8.158 \AA, \mathrm{b}_{\mathrm{o}}=12.342 \AA$, and $\mathrm{c}_{\mathrm{o}}$ $=14.452 \AA \quad$ (102 atoms per cell, Fig. 1(a)). ${ }^{37,38}$

The $o-\mathrm{Al}_{13} \mathrm{Co}_{4}$ compound is known to be unstable at low temperatures, but stabilized at higher temperatures by the entropy of $\mathrm{Al}$ vacancy hopping and low frequency vibrational modes. ${ }^{39}$ Monoclinic $m-\mathrm{Al}_{13} \mathrm{Co}_{4}$ crystallizes in the $C 2 / m$ space group (No. 12, Pearson symbol $m C 102)$ with the lattice parameters: $\mathrm{a}_{\mathrm{m}}$ $=15.173 \AA, \mathrm{b}_{\mathrm{m}}=8.109 \AA, \mathrm{c}_{\mathrm{m}}=12.349 \AA$ and $\beta=107.84^{\circ} .{ }^{40}$ Because of the relatively close structures of orthorhombic and monoclinic $\mathrm{Al}_{13} \mathrm{Co}_{4}$, their coexistence is possible and can give rise to defects. Metadislocations, due to plastic deformations, ${ }^{41-44}$ as well as twins (Fig. S1), ${ }^{45}$ are frequent in complex intermetallic phases. Twins in $\mathrm{Al}_{13} \mathrm{Co}_{4}$ are generally related to orthorhombic/monoclinic interfaces. In the following, ideal structures with full atomic occupations are considered.

The $\mathrm{Al}_{13} \mathrm{Co}_{4}$ monoclinic and orthorhombic structures are approximant structures to decagonal d-AlNiCo quasicrystals, the $o$-[100] and $m$-[010] directions being identified as the pseudo-tenfold directions, in $o-\mathrm{Al}_{13} \mathrm{Co}_{4}$ and

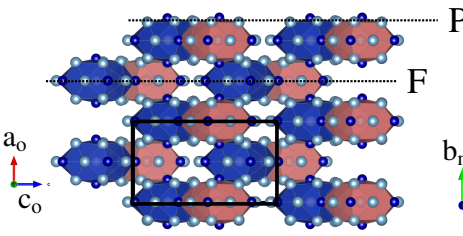

(a)

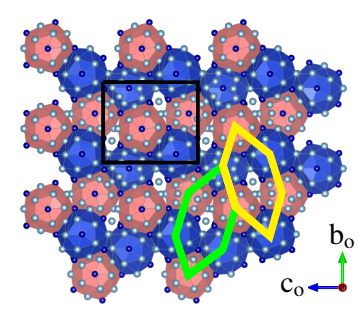

(c)

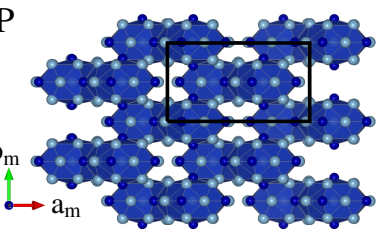

(b)

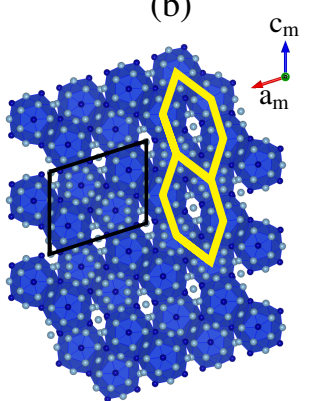

(d)
Figure 1: Bulk structure of (a) $o-\mathrm{Al}_{13} \mathrm{Co}_{4}$ along the $o$-[010] direction showing the Henley-type clustering (in red and blue, both clusters are not crystallographically equivalent, the $\mathrm{Al}$ atoms in the center of the clusters do not have the same Wyckoff position, see section S3 of the supporting information) as well as the stacking structure of F-type and P-type atomic planes, (b) $m$ - $\mathrm{Al}_{13} \mathrm{Co}_{4}$ along the $m$-[001] direction showing the Henley-type clustering (in blue, all the clusters are crystallographically equivalent, the $\mathrm{Al}$ atoms in the center of the clusters have the same Wyckoff position, see section $\mathrm{S} 3$ of the supporting information), (c) $o-\mathrm{Al}_{13} \mathrm{Co}_{4}$ along the pseudo-tenfold axis (the squashed-hexagonal tile, obtained by connecting together all Co atoms of the P-type plane, is highlighted in yellow and green) and (d) $m-\mathrm{Al}_{13} \mathrm{Co}_{4}$ structure along the pseudo-tenfold axis. Unlike $o-\mathrm{Al}_{13} \mathrm{Co}_{4}$ all hexagons of the hexagonal tile in the P-type plane have the same orientation in $m-\mathrm{Al}_{13} \mathrm{Co}_{4}$. The unit cells, $\mathrm{Al}$ and Co atoms are drawn in black, light blue and dark blue, respectively. 
$m$ - $\mathrm{Al}_{13} \mathrm{Co}_{4}$, respectively. Their bulk structures are described as a pile of two types of planes, perpendicular to the pseudo-tenfold axis, labeled alternatively flat-type (F-type) and puckered-type (P-type) planes (Fig. 1(a)). The stacking sequence is $\mathrm{F}_{0} \mathrm{P}_{0.25} \mathrm{~F}_{0.5} \mathrm{P}_{0.75}$ and the interlayer distance is approximately $2 \AA$. On the other hand, the approximant structure can be understood as a stacking of Henley-type clusters (in red and blue in Fig. 1(ab)) where the F-type planes intercept the clusters in their meridian plane. The linear molecular group $\mathrm{Co}-$ $\mathrm{Al}-\mathrm{Co}$, parallel to the pseudo-tenfold axis, is characterized by quite strong and covalent-like bonds. ${ }^{2,46,47}$ The orthorhombic and monoclinic phases differ in the relative cluster arrangements. It is highlighted in Fig. 1(cd) by the hexagonal-like tilings obtained by connecting together the Co atoms located in the P-type plane. In the monoclinic phase, all the hexagonal tiles point towards the same direction whereas they change orientation every other hexagon in the orthorhombic phase (Figs. 1(c) and 1(d)).

\section{Experimental methods}

We used an orthorhombic $o-\mathrm{Al}_{13} \mathrm{Co}_{4}$ single crystal, grown from an aluminum rich solution using the Czochralski process. The ingot was oriented using back scattered x-ray Laue diffraction and cut perpendicular to the $o$-[010] direction. The sample was then polished using diamond paste down to $0.25 \mu \mathrm{m}$, as in our previous studies. ${ }^{30,34}$

The sample was prepared in situ under ultra-high vacuum (UHV) conditions by cycles of $\mathrm{Ar}^{+}$sputtering ( $1.5 \mathrm{kV}$ for 30 minutes) followed by annealing between $873 \mathrm{~K}$ and $1073 \mathrm{~K}$ for 1 hour. The surface temperature has always been controlled using an infrared pyrometer (surface emissivity set to 0.3 ). The surface composition and cleanliness was ascertained using Xray Photoelectron Spectroscopy (XPS, before Scanning Tunneling Microscopy (STM) analyses) or Auger Electron Spectroscopy (AES, before SXRD experiments). Low Energy Electron Diffraction (LEED) patterns were recorded from $1 \mathrm{eV}$ to $300 \mathrm{eV}$ to check the surface orientation and the surface preparation under UHV. Atomic Force Microscopy (AFM) analyses were achieved at room conditions (pressure and temperature) with a Nano-I AFM from Pacific Nanotechnology Inc. used in close contact mode with a Si tip.

Surface diffraction measurements were performed at the Surfaces and Interfaces X-ray Scattering (SixS) beamline at Synchrotron SOLEIL. In SixS setup, the UHV preparation chamber (LEED, AES) is coupled with a UHV measurement chamber. The latter is mounted on a Z-axis diffractometer. ${ }^{48,49}$ Thanks to this setup, the transfer of the sample into the diffraction chamber is done without any surface deterioration. SXRD measurements were carried out at an energy of $18.41 \mathrm{keV}$ and an incident angle of $\mu=0.3^{\circ}$. A 2D hybrid pixel detector (XPAD S140) was used to collect the scattered intensities ${ }^{50}$ and BINoculars program to process the whole data set. ${ }^{51}$

AVE and ROD softwares (from the ANAROD suite $^{52}$ ) were used to analyze the processed data generated by BINoculars. Several crystal truncation rods (CTRs) were extracted. Structure factors of CTRs were simulated from DFT-relaxed surface models. The adequacy of the simulated CTRs intensities with the experimental data is quantified by the $\chi^{2}$ factor :

$$
\chi^{2}=\frac{1}{N_{d a t a}-N_{p}} \sum\left|\frac{I_{e x p}-I_{t h}}{\sigma}\right|^{2}
$$

where $N_{\text {data }}$ is the number of data points, $I_{\text {exp }}$ (resp. $I_{t h}$ ) the experimental intensity (resp. simulated intensity), $N_{p}$ the number of refined parameters and $\sigma$ the estimated error bar. In our case, only the scale factor is refined $\left(N_{p}=1\right)$. Miller indices will further be referred to $\mathrm{H}, \mathrm{K}$ and $\mathrm{L}$ (surface unit cell, orthorhombic structure).

\section{Computational methods}

DFT calculations were performed using the Vienna $a b$ initio simulation package (VASP). ${ }^{53}$ We applied the spin polarized projector-augmented wave method, ${ }^{54,55}$ to describe the interactions between the valence electrons and the ionic core. We used the DFT-D3 approximation, ${ }^{56,57}$ because van der Waals forces are present at metallic surfaces, and they non negligibly affect the surface energies. ${ }^{58}$ We considered atomic valences to be $3 s^{2} 3 p^{1}$ (Al) and $3 d^{8} 4 s^{1}$ (Co). Total energies were minimized until the energy differences were less than $10^{-6} \mathrm{eV}$ between two electronic cycles. Atomic structures - plotted using the VESTA software ${ }^{59}$ - were relaxed until the Hellmann-Feynman forces were as low as $0.02 \mathrm{eV} / \AA$. Calculations were performed using a 450 $\mathrm{eV}$ cut-off energy $\left(\mathrm{E}_{\text {cut }}\right)$ and $\Gamma$-centered $13 \times 9 \times 7$ and $7 \times 13 \times 1$ Monkhorst-Pack grids for bulk and surface calculations, respectively. Those parameters were chosen to achieve a precision for the total energy lower than $0.1 \mathrm{meV} /$ atom. They result in cohesive energies for $f c c$ $\mathrm{Al}\left(E_{\mathrm{coh}}^{\mathrm{Al}}=-3.67 \mathrm{eV} / \mathrm{at}.\right)$ and $h c p \mathrm{Co}\left(E_{\mathrm{coh}}^{\mathrm{Co}}=-5.50\right.$ $\mathrm{eV} / \mathrm{at})$ in good agreement with the experimental data $\left(E_{\mathrm{coh}}^{\mathrm{Al}}=-3.39 \mathrm{eV} /\right.$ at. and $E_{\mathrm{coh}}^{\mathrm{Co}}=-5.44 \mathrm{eV} /$ at. $)$. This is the same for the formation enthalpy of orthorhombic $o-\mathrm{Al}_{13} \mathrm{Co}_{4}\left(\Delta H_{f}^{\mathrm{Al}_{13} \mathrm{Co}_{4}}=-0.412 \mathrm{eV} /\right.$ at (calc) and $\Delta H_{f}^{\mathrm{Al}_{13} \mathrm{Co}_{4}}=-0.41 \mathrm{eV} /$ at $\left.(\exp )^{60}\right) . \quad$ Relaxed bulk structures are detailed in section S3 of the supporting information. STM images were simulated using the Tersoff-Hamann approximation. ${ }^{61}$

The approach used to compute surface energies in this work is the typical symmetric slab model, ${ }^{62,63}$ already used in our previous studies, ${ }^{35,64}$ wherein a supercell of the crystal oriented to expose its $(h k \ell)$ surface is generated, and atoms are removed from a portion of the supercell to create a vacuum (16 to $24 \AA$ thick symmetric slabs, void thickness $\simeq 16 \AA$ ). This set-up for surface modeling leads to surface energies converged within less than $2.0 \mathrm{~mJ} / \mathrm{m}^{2}$. In most cases, the stoichiometries 
of our surface models are different from the bulk one. Surface energies are then determined as a function of the chemical potentials $\left(\mu_{\mathrm{Al}}, \mu_{\mathrm{Co}}\right)$ and number of atoms $\left(N_{\mathrm{Al}}, N_{\mathrm{Co}}\right)$ in the slab: ${ }^{65}$

$$
\gamma_{(h k \ell)}^{\sigma}=\frac{E_{s l a b(h k \ell)}^{\sigma}-N_{\mathrm{Al}} \mu_{\mathrm{Al}}-N_{\mathrm{Co}} \mu_{\mathrm{Co}}}{2 A_{\text {slab }(h k \ell)}}
$$

In the previous equation, the numerator can be understood as the difference between the total energy of the slab and the energy of the corresponding "bulk" with the same stoichiometry. The Al and Co chemical potentials in $f c c \mathrm{Al}$ and $h c p \mathrm{Co}\left(\mu_{A l}^{b u l k}\right.$ and $\mu_{C o}^{b u l k}$, respectively) are taken as the cohesive energies calculated at $T=0$ $\mathrm{K} .{ }^{65}$ In the case of $\mathrm{o}-\mathrm{Al}_{13} \mathrm{Co}_{4}$, the $\mathrm{Al}$ and Co chemical potentials are given by the Gibbs phase rule :

$$
\begin{aligned}
\mu_{o-\mathrm{Al}_{13} \mathrm{Co}_{4}}^{\text {bulk }} & =13 \mu_{\mathrm{Al}}+4 \mu_{\mathrm{Co}} \\
& =13 \mu_{\mathrm{Al}}^{\text {bulk }}+4 \mu_{\mathrm{Co}}^{\text {bulk }}+\Delta H_{f}^{o-\mathrm{Al}_{13} \mathrm{Co}_{4}}
\end{aligned}
$$

Because the surface is considered to be in equilibrium with the underlying $o-\mathrm{Al}_{13} \mathrm{Co}_{4}$ bulk, they are constrained in a range, that is $\frac{17}{13} \Delta H_{f}^{\mathrm{Al}_{13} \mathrm{Co}_{4}} \leq \mu_{A l}-\mu_{A l}^{b u l k} \leq$ 0 . Formation energies of orthorhombic/monoclinic and monoclinic/monoclinic interfaces have been calculated as well, using :

$$
E_{\mathrm{int}}^{\mathrm{m} / i}=E_{\text {tot }}^{\text {supercell }}-E_{\text {tot }}^{\mathrm{m}}-E_{\text {tot }}^{i}
$$

where $E_{\text {int }}^{\mathrm{m} / i}, E_{\text {tot }}^{\mathrm{m}}$ and $E_{\text {tot }}^{i}$ are the total energies of the supercell (Fig. S1(a-b)), the monoclinic cell and the $i$-type cell $(i \in\{o, m\})$, respectively.

The adsorption properties of the different surface structures considered in this work have been computed through potential energy maps. The adsorption has been computed on specific points of regular grids covering the surfaces. For each specific point, all degrees of freedom of the uppermost layers and the $z$ coordinate of the adsorbed hydrogen atom have been allowed to relax during the geometry optimizations, whereas the $x$ and $y$ adsorbate coordinates have been frozen. The adsorption energy $\left(\Delta E_{a d s}\right)$ on the considered $\mathrm{Al}_{13} \mathrm{Co}_{4}$ surfaces is defined as follows :

$$
\Delta E_{a d s}=E(\mathrm{H} / \mathrm{slab})-E(\text { slab })-\frac{1}{2} E\left(\mathrm{H}_{2}\right)
$$

where $E(\mathrm{H} / \mathrm{slab}), E($ slab $)$ and $E\left(\mathrm{H}_{2}\right)$ are the total electronic energy of the adsorbed system, the bare support surface and the gas phase $\mathrm{H}_{2}$ molecule, respectively. For each surface, a potential energy map is built by an interpolation over the series of adsorption energies calculated for each point of the grid.

\section{Results and discussions}

\section{LEED - AFM - STM analyses}

According to LEED measurements, a $(1 \times 1)$ surface structure is mainly observed (Fig. 2(a), Fig. S6a). Dif- fuse scattering resembling a $(2 \times 1)$ and a $(3 \times 1)$ surface reconstructions is also visible beside the $(1 \times 1)$ surface structure. When scanning the energy range $1-300 \mathrm{eV}$, secondary peaks appear and move away from the center in between the main diffraction spots. They are attributed to the presence of facets at the surface. Continuous intensity can also be seen in between the main diffraction spots. This signal could be linked to line or planar defects such as metadislocations or interfaces close to the surface.

According to AFM, a columnar structure appears along the $o-[100]$ direction as shown in Fig. 2(b) (Fig. S6b). This feature is similar to that observed at the (12110) and (10000) two-fold $d$-Al-Ni-Co quasicrystalline surfaces, ${ }^{17}$ revealing faceting at the $o$ $\mathrm{Al}_{13} \mathrm{Co}_{4}(010)$ surface. According to STM, terraces extend over a few hundreds of nanometers, separated by a single-step height equal to $6.1 \pm 0.2 \AA$, i.e. corresponding to half of the lattice parameter $\left(\mathrm{b}_{\mathrm{o}} / 2=6.17 \AA\right)$. Highresolution images (Fig. 2(c), Fig. S6c) show a mixture of three different surface reconstruction motifs, in agreement with the LEED pattern, randomly distributed on the sample surface : $(1 \times 1),(2 \times 1)$ and $(3 \times 1)$. These reconstructions may be due to local vacancies stabilization. For the $(1 \times 1)$ surface structure, a triangular motif is observed.

\section{SXRD analysis}

A large part of the reciprocal space was completely measured during the SXRD experiment: $\left|\mathrm{H}_{\max }\right|=9.5$, $\left|\mathrm{K}_{\max }\right|=5.5$ and $\mathrm{L}_{\max }=4.8$. The $o$-(010) surface orientation is confirmed by the in-plane reciprocal space map of ${ }^{o-} \mathrm{Al}_{13} \mathrm{Co}_{4}$ (Fig. 3(a)). A total of 34 inequivalent CTRs were extracted from the measured reciprocal space region and further compared to DFT-based simulations using different surface structure models (see section page 6$)$. Fig. 3(b) presents two out-of-plane $(\mathrm{H}, \mathrm{L})$ reciprocal space maps of $o-\mathrm{Al}_{13} \mathrm{Co}_{4}(010)$ at $\mathrm{K}=2$ and $\mathrm{K}$ $=3$. The facets' signal is clearly visible in the map at $\mathrm{K}$ $=2$ : the facets' rods make an angle of $54.2^{\circ}$ with the direction normal to the surface (indicated with green and red arrows in Fig. 3(b)). The facet's rods do no intercept each other at the Bragg peaks of the orthorhombic structure (labeled with black circles), meaning that the facets do not present the $o-\mathrm{Al}_{13} \mathrm{Co}_{4}$ structure. Facets are therefore related to the $m-\mathrm{Al}_{13} \mathrm{Co}_{4}$ structure. Two types of twins are considered, the positions of their respective diffraction peaks are plotted in red and green circles (Fig. 3(b)). The facets' rods intercept the $m$ $(\overline{2} 21)$ diffraction peaks. The facets are therefore consistent with a $m-(\overline{2} 01)$ orientation. Their signal is less clearly visible on the maps at an odd value of $K$ but is still present. These conclusions are consistent with the fairly continuous intensity measured in between Bragg peaks along the $\mathrm{H}$ direction for integer values of $\mathrm{K}$ and L (similar observation as in LEED measurements, Figs. $2,3)$. This kind of signal can be produced by planar defects such as interfaces between two phases. It is 


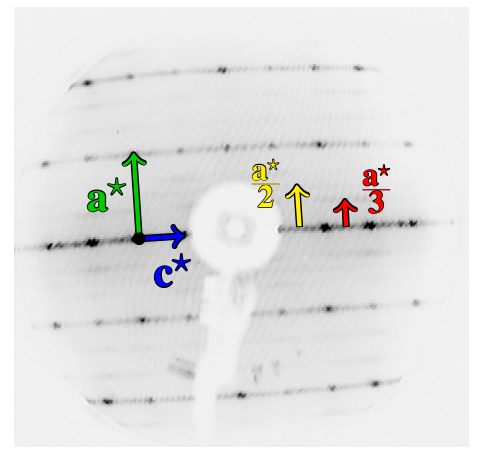

(a) LEED pattern

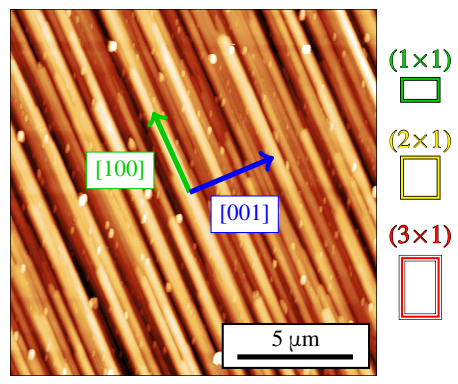

(b) AFM image

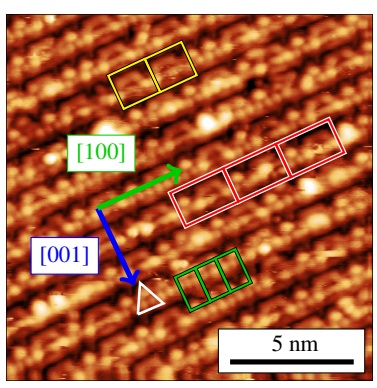

(c) STM image
Figure 2: (a) LEED pattern measured at $30 \mathrm{eV}$. Diffuse scattering resembling a $(2 \times 1)$ and a $(3 \times 1)$ surface reconstructions are shown in yellow and red arrows, respectively. (b) AFM image of $o-\mathrm{Al}_{13} \mathrm{Co}_{4}(010)\left(15 \times 15 \mu \mathrm{m}^{2}\right)$ showing a columnar and faceted structure. (c) STM image of a flat terrace at the $o-\mathrm{Al}_{13} \mathrm{Co}_{4}(010)$ surface $\left(15 \times 15 \mathrm{~nm}^{2}\right)$ at $\mathrm{V}_{\mathrm{b}}$ $=0.6 \mathrm{~V}$. The $(1 \times 1),(2 \times 1)$ and $(3 \times 1)$ cells are drawn in green, yellow and red, respectively. A triangular motif is highlighted in white.

reasonable to assume these planar defects to be monoclinic/orthorhombic interfaces.

The formation of monoclinic/orthorhombic interfaces is calculated to be exothermic $\left(E_{\text {int }}^{\mathrm{m} / \mathrm{o}}=-4 \mathrm{~mJ} / \mathrm{m}^{2}\right)$. Thus, they stabilize the structure, which may explain why they are naturally and profusely present in the bulk compound. For comparison, the formation energy of monoclinic/monoclinic interfaces is endothermic $\left(E_{\mathrm{int}}^{\mathrm{m} / \mathrm{m}}=50 \mathrm{~mJ} / \mathrm{m}^{2}\right)$.

Additional information can be extracted from SXRD. Intensity is observed in between integer values of $\mathrm{K}$ (indicated by a yellow rectangle in Fig. 3(a) for $\mathrm{K}=3.5$ ). Complementary SXRD analysis suggests that this signal arises from a bulk defect and not from the surface itself. Other distinct features can be seen in the map $(\mathrm{H}, \mathrm{L})$ for $\mathrm{K}=2$ and a few examples of them are framed in orange in Fig. 3(b). They are neither part of the orthorhombic nor of the monoclinic (facets) lattices. Some complementary simulations of the reciprocal space - Fourier transform of a model atomic structure - suggest that they may be generated by metadislocations close to the surface (section S1, Figs. S2-S3 of the supporting information).

To summarize, the SXRD analysis led to a macro- scopic surface structure model for of $o-\mathrm{Al}_{13} \mathrm{Co}_{4}(010)$. It consists in a coexistence of orthorhombic (flat terraces) and monoclinic (facets) structures at the surface separated by monoclinic/orthorhombic interfaces, as well as the possible presence of metadislocations close to the surface (Fig. 4).

\section{Surface energy calculations}

\section{$o-\mathrm{Al}_{13} \mathrm{Co}_{4}(010)$}

Bulk o- $\mathrm{Al}_{13} \mathrm{Co}_{4}$ cannot be described as a stacking of well-separated atomic layers along the $o$-[010] direction (Fig. 5(a)). Our strategy to build surface models was then the following: first, eight bulk truncated models almost regularly spaced along [010] - were considered (labeled $\mathrm{O}_{0}$ to $\mathrm{O}_{5.7}$, depending on the distance in $\AA$ to the center of the cell, e.g. $0.6 \AA$ ), before we refine the most stable models identified in the first step. Variations of models $\mathrm{O}_{0.6}$ and $\mathrm{O}_{1.2}$ (named $\mathrm{O}_{0.6}^{i}$ and $\mathrm{O}_{1.2}^{i}$ ) were then considered. Thus, a total of 17 models were investigated. Their surface atomic structures are drawn in Fig. 5(b). Because of the symmetry (glide mirror) along $o$-[010], only half of a unit cell was investigated.

The surface energies of the considered models are summarized in Fig. 6. Less stable models, i.e. $\mathrm{O}_{1.2}^{3}$ and $\mathrm{O}_{3.6}$, with the largest surface energies (between 2.2 and $2.38 \mathrm{~J} / \mathrm{m}^{2}$ ), as well as $\mathrm{O}_{1.2}^{1}, \mathrm{O}_{1.2}^{2}, \mathrm{O}_{1.2}^{4}$ and $\mathrm{O}_{2.7}$, with surface energies ranging from 1.86 to $2.24 \mathrm{~J} / \mathrm{m}^{2}$, present low atomic density terminations combined with the presence of isolated Co. The surface energies for models with higher surface atomic density $\left(\mathrm{O}_{0.6}, \mathrm{O}_{0.6}^{i}\right.$, $\mathrm{O}_{1.9}, \mathrm{O}_{4.8}$ and $\mathrm{O}_{5.7}$ ) are smaller: they range from 1.72 to $2.02 \mathrm{~J} / \mathrm{m}^{2}$. Several models keep intact at their surface the strong covalent-like $\mathrm{Co}-\mathrm{Al}-\mathrm{Co}$ linear molecular groups : $\mathrm{O}_{0}, \mathrm{O}_{0.6}^{1}, \mathrm{O}_{0.6}^{4}, \mathrm{O}_{1.2}, \mathrm{O}_{1.2}^{1}$ and $\mathrm{O}_{1.2}^{2}$. They are found to be amongst the 8 most stable surface models for the whole range of allowed chemical potentials. The surface energy of the most stable model $\left(\mathrm{O}_{0}\right)$ is quite lower than the other considered models. It does not depend on the chemical potentials $\left(1.66 \mathrm{~J} / \mathrm{m}^{2}\right)$, since the stoichiometry of the slab used for the calculation is the one of the bulk crystal. It is described as a flat termination consisting of rows of protruding triangular motifs made of aluminum atoms separated by a $6.5 \AA$ gap, while maintaining intact the strongly bound $\mathrm{Co}-\mathrm{Al}-\mathrm{Co}$ molecular group at the surface.

\section{$m-\mathrm{Al}_{13} \mathrm{Co}_{4}(\overline{2} 01)$}

Experimental SXRD measurements identified facets as $m-\mathrm{Al}_{13} \mathrm{Co}_{4}(\overline{2} 01)$. As previously, 17 bulk truncated models - Fig. 7(a) - were built, by progressively removing atoms at the surface (labeled $\mathrm{M}_{0}$ to $\mathrm{M}_{7.2}$ with a step of $0.45 \AA$, depending on the distance in $\AA$ to the center of the cell, e.g. $7.2 \AA$ ). Due to the symmetry of the monoclinic lattice, only half of the cell was considered. Models $\mathrm{M}_{0}$ to $\mathrm{M}_{1.35}$ are Al-rich surface models with a progressively increasing surface atomic density. Models $\mathrm{M}_{1.8}$ to $\mathrm{M}_{3.15}$, as well as models $\mathrm{M}_{6.75}$ and $\mathrm{M}_{7.2}$ have 


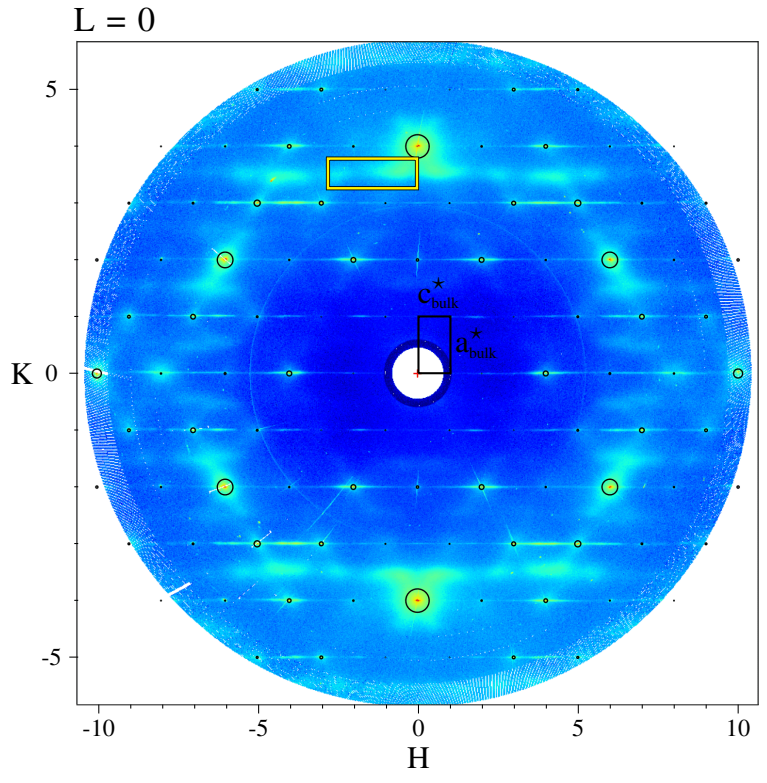

(a)
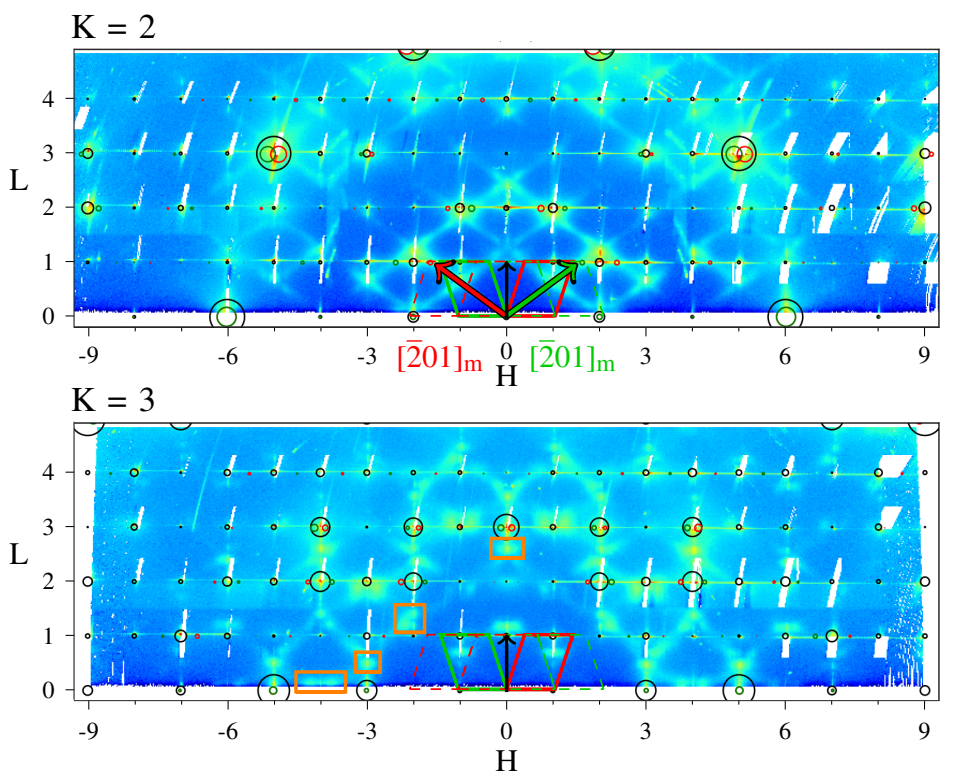

(b)

Figure 3: (a) In-plane $(\mathrm{H}, \mathrm{K})$ reciprocal space map of $o-\mathrm{Al}_{13} \mathrm{Co}_{4}$. The diffraction spots of the orthorhombic phase are indexed with black circles. The region presented in Fig. S2 is drawn in red. (b) Out-of-plane (H,L) - for $\mathrm{K}=2$ and $\mathrm{K}=3$ respectively - reciprocal space maps of $o-\mathrm{Al}_{13} \mathrm{Co}_{4}$. The position of the monoclinic diffraction spots are represented in green and red circles (two different twins). Facets appear to present the $m-(\overline{2} 01)$ orientation. Blank regions are areas where the signal was too intense to be collected (too close to Bragg peaks).

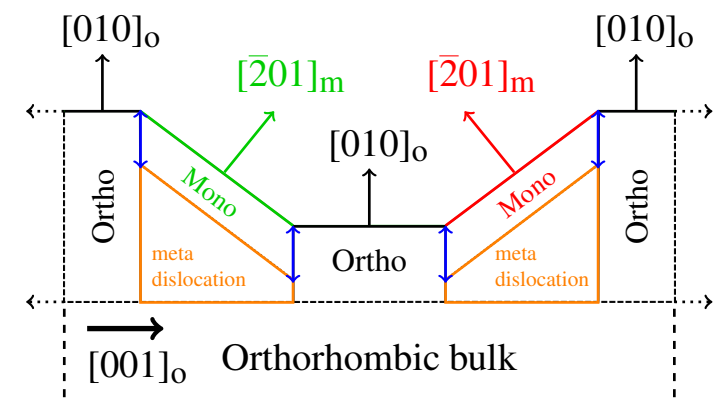

Figure 4: Schematic of the suggested surface model based on the experimental observations. Orthorhombic flat terraces and monoclinic facets coexist in this model and are drawn in black and red/green (two different twins), respectively. Monoclinic/orthorhombic interfaces are represented in blue. Metadislocations are displayed in orange.

dense Co-rich terminations, while models $\mathrm{M}_{3.6}$ to $\mathrm{M}_{6.3}$ are less dense with a few Co atoms in the surface plane. The strong $\mathrm{Co}-\mathrm{Al}-\mathrm{Co}$ covalent-like bond is kept intact at the surface in models $\mathrm{M}_{2.7}, \mathrm{M}_{3.15}, \mathrm{M}_{4.95} \mathrm{M}_{5.4}, \mathrm{M}_{5.85}$.

Surface energy calculations are summarized in Fig. 8. $\mathrm{M}_{1.8}$ presents the highest surface energy (ranging from 1.91 to $2.39 \mathrm{~J} / \mathrm{m}^{2}$ ) due to a low atomic surface density combined with a Co-rich composition. In the Co-rich limit, the model $\mathrm{M}_{3.15}$, which has a dense termination plane (highest surface atomic density 0.19 at $/ \AA^{2}$ ) and keeps intact the strong $\mathrm{Co}-\mathrm{Al}-\mathrm{Co}$ covalent-like bond at the surface, clearly presents the lowest surface energy $\left(1.19 \mathrm{~J} / \mathrm{m}^{2}\right)$. In the Al-rich limit, four models present rather low surface energies: models $\mathrm{M}_{5.85}, \mathrm{M}_{3.15}, \mathrm{M}_{1.35}$ and $\mathrm{M}_{0.9}$. The most stable ones are the Al-rich models $\left(\mathrm{M}_{1.35}\right.$ and $\left.\mathrm{M}_{0.9}\right)$, with a similar surface energy (1.25 $\mathrm{J} / \mathrm{m}^{2}$ ). The $\mathrm{M}_{3.15}$ surface model is the most stable one over the longest range of $\mathrm{Al}$ chemical potentials and therefore will be considered for further investigations.

\section{Detailed surface model for the pseudo- twofold surface of $o-\mathrm{Al}_{13} \mathrm{Co}_{4}$}

As presented in Fig. 4, the twofold surface of $\mathrm{Al}_{13} \mathrm{Co}_{4}$ consist in terraces of $o-\mathrm{Al}_{13} \mathrm{Co}_{4}(010)$ and facets, identified as $m-\mathrm{Al}_{13} \mathrm{Co}_{4}(\overline{2} 01)$. Focusing on the $o$ $\mathrm{Al}_{13} \mathrm{Co}_{4}(010)$ surface, the $\mathrm{O}_{0}$ model (Fig. S7) has been identified as a stable surface model with a rather low surface energy $\left(1.66 \mathrm{~J} / \mathrm{m}^{2}\right)$. To complete the thermodynamic approach, STM images (Fig. 9) and SXRD rods (Fig. 10, Tab. 1) are simulated using stable surface models.

Theoretical STM images are compared to both the experimental measurements and their filtered (2D FFT) counterparts. On the 2D FFT filtered image, rows of triangular motifs separated by a $0.65 \mathrm{~nm}$ gap are observed. Only five models reproduce relatively well this feature : $\mathrm{O}_{0}, \mathrm{O}_{0.6}^{3}, \mathrm{O}_{0.6}^{5}, \mathrm{O}_{1.2}^{3}$ and $\mathrm{O}_{1.2}^{4}$, because the atomic arrangement at the surface include a triplet made of either $\mathrm{Al}_{3}$ or $\mathrm{CoAl}_{2}$ atomic ensembles. In most cases - the $\mathrm{O}_{0}, \mathrm{O}_{0.6}^{3}$ and $\mathrm{O}_{0.6}^{5}$ are good examples - the bright/dark protrusions are due to atoms slightly above/below the mean position of the termination plane. So far, the STM image simulated using the $\mathrm{O}_{0}$ or $\mathrm{O}_{1.2}^{4}$ models show the best agreement with the experimental one. 


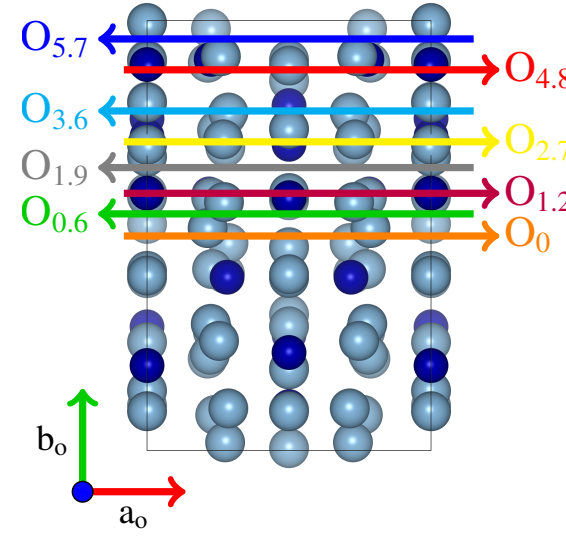

(a)
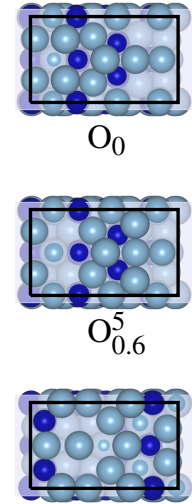

$\mathrm{O}_{1.9}$
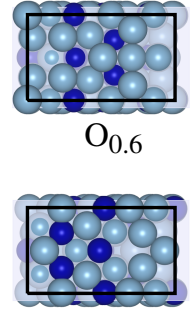

$\mathrm{O}_{1.2}$

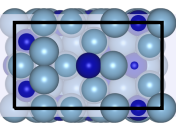

$\mathrm{O}_{2.7}$
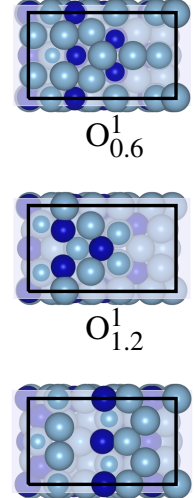

$\mathrm{O}_{3.6}$
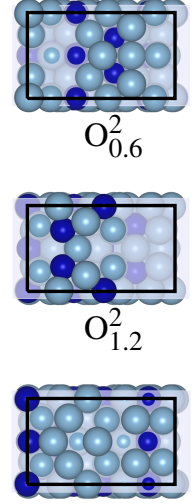

$\mathrm{O}_{4.8}$
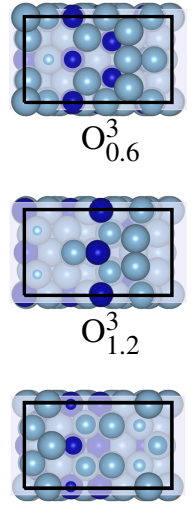

$\mathrm{O}_{5.7}$
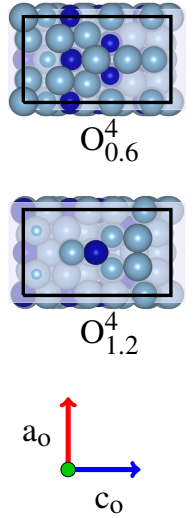

(b)

Figure 5: (a) Bulk truncation models that were considered. (b) Surface structure models $\mathrm{O}_{0}$ to $\mathrm{O}_{5.7}$. Unit cells, $\mathrm{Al}$ and $\mathrm{Co}$ atoms are drawn in black, light blue and dark blue, respectively.

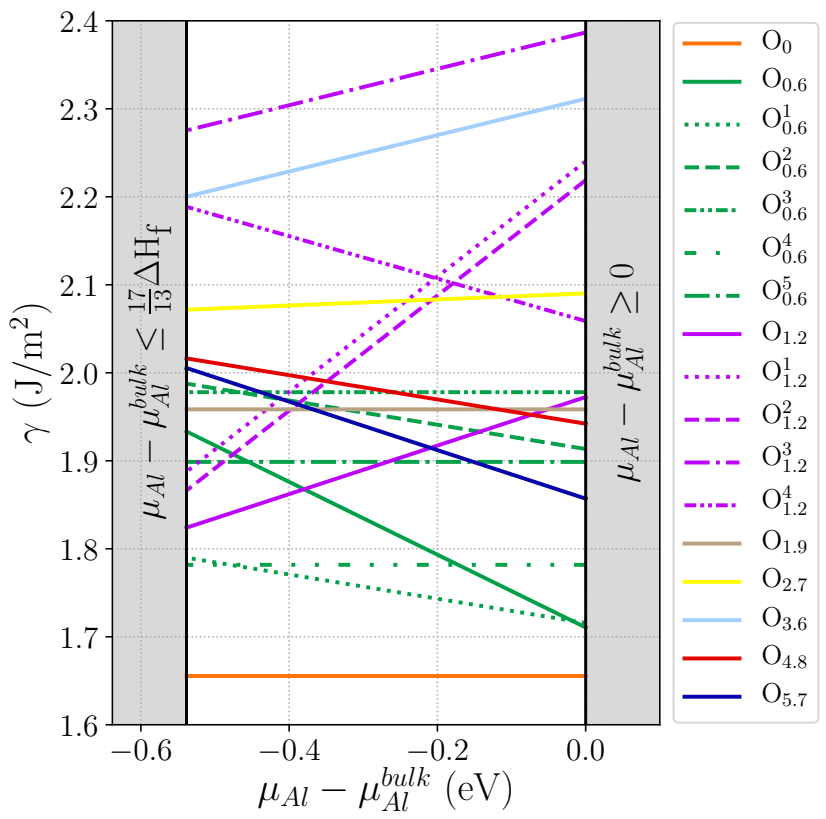

Figure 6: Surface energies of 17 surface models for $O$ $\mathrm{Al}_{13} \mathrm{Co}_{4}(010)$ as a function of $\mu_{A l}-\mu_{A l}^{\text {bulk }}$.
The structure factors of the 34 inequivalent CTRs extracted from the X-ray diffraction measurements were simulated using the DFT-relaxed surface models. Four models were tested $\left(\mathrm{O}_{0}, \mathrm{O}_{0.6}, \mathrm{O}_{0.6}^{1}\right.$ and $\left.\mathrm{O}_{1.2}^{4}\right)$ based on the surface energy calculations and the STM image simulations. As shown in Tab. $1, \mathrm{O}_{0}$ is overall the best fitting surface model having the lowest $\chi^{2}$ and R-factor values (Fig. 10) and reproduce quite well a lot of observed features. This model consists in a flat termination with rows along the [100] (pseudo-tenfold) direction, made of protruding triangular motifs of aluminum atoms separated by a $6.5 \AA$ gap. The strong anisotropy in the surface plane may reflect the one observed on twofold surfaces of decagonal quasicrystals, spanned by perpendicular periodic and aperiodic axes. Focusing on the facets, the $\mathrm{M}_{3.15}$ surface model (Fig. S8) is the most stable one over the longest range of $\mathrm{Al}$ chemical potentials. A deep pseudo-gap at the Fermi energy is also identified in the corresponding density of states, which shows similar features to that of the $\mathrm{O}_{0}$ model.

Table 1: X-ray diffraction results - ROD analysis.

\begin{tabular}{ccccc}
\hline Surface Model & $\mathbf{O}_{\mathbf{0}}$ & $\mathrm{O}_{0.6}$ & $\mathrm{O}_{0.6}^{1}$ & $\mathrm{O}_{1.2}^{4}$ \\
\hline Scale factor & 0.0197 & 0.0199 & 0.0198 & 0.0189 \\
$\chi^{2}$ & $\mathbf{6 . 1 0 7}$ & 6.137 & 7.145 & 7.269 \\
\hline
\end{tabular}

Now that the structure of the pseudo-twofold surface is known, it is of interest to compare its stability to the one of the pseudo-tenfold surface. Without regarding the facets, the relative stabilities of the pseudo-twofold $\left(\mathrm{O}_{0}\right.$ model $)$ and pseudo-tenfold surfaces rely on the $\mathrm{Al}$ chemical potential (Fig. 11). Two surface models are available for the pseudo-tenfold surface: a dense $\mathrm{Al}$ rich flat plane, identified by a combination of surface science studies and DFT calculations $\left(\mathrm{P}_{24}\right),{ }^{32-34}$ and a highly corrugated model, keeping intact the Henleytype clusters at the surface $\left(\mathrm{P}_{14}\right),{ }^{24,35,46}$ build by a 


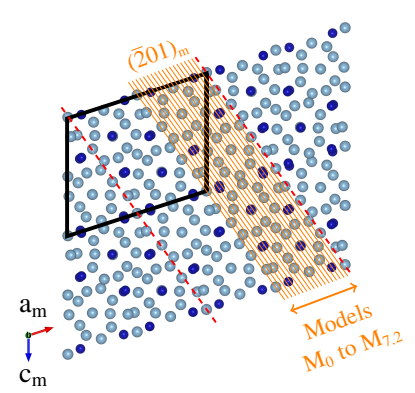

(a)

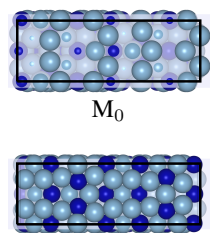

$\mathrm{M}_{2.7}$

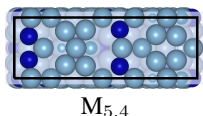

$\mathrm{M}_{5.4}$

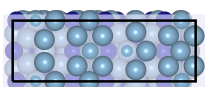

$\mathrm{M}_{0.45}$

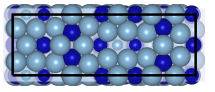

$\mathbf{M}_{3.15}$

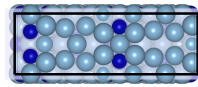

$\mathrm{M}_{5.85}$

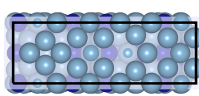

$\mathrm{M}_{0.9}$

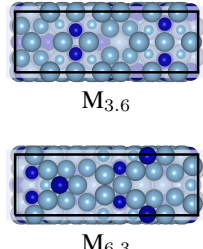

$\mathrm{M}_{6.3}$

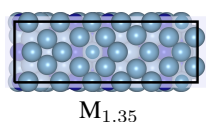

$\mathbf{M}_{1.35}$

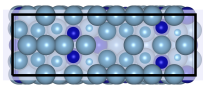

$\mathrm{M}_{4.05}$

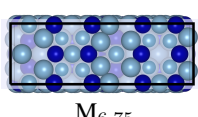

(b)

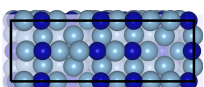

$\mathrm{M}_{1.8}$

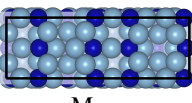

$\mathrm{M}_{2.25}$
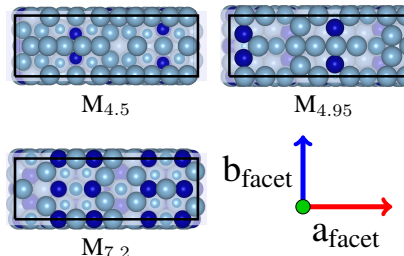

Figure 7: (a) Bulk (monoclinic structure) truncation models considered in this work. (b) Surface structures of models $\mathrm{M}_{0}$ and $\mathrm{M}_{7.2}$. Unit cells, $\mathrm{Al}$ and $\mathrm{Co}$ atoms are drawn in black, light blue and dark blue, respectively.

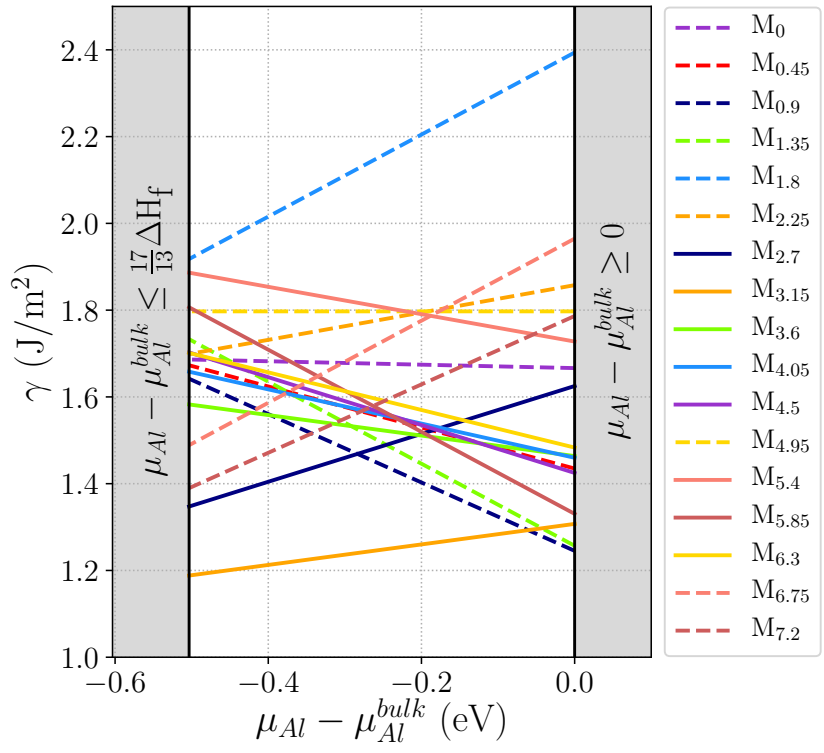

Figure 8: Surface energies of 17 surface models for $m$ $\mathrm{Al}_{13} \mathrm{Co}_{4}(\overline{2} 01)$ as a function of $\mu_{A l}-\mu_{A l}^{b u l k}$.

theoretical cleavage (Figs. S4-S5). In the Al-rich region $\left(0>\mu_{A l}-\mu_{A l}^{b u l k}>-0.16 \mathrm{eV}\right)$, the pseudo-tenfold surface $\left(\mathrm{P}_{24}\right.$ model $)$ is more stable than the pseudotwofold one $\left(\mathrm{O}_{0}\right.$ model $)$. The situation is quite different in the Co-rich region, $\left(\frac{17}{13} \Delta H_{f}<\mu_{A l}-\mu_{A l}^{b u l k}<-0.16\right.$ $\mathrm{eV}$ ), where the surface energies of the pseudo-twofold $\left(\mathrm{O}_{0}\right.$ model $)$ and pseudo-tenfold $\left(\mathrm{P}_{14}\right.$ model $)$ surfaces are very close, thus suggesting a similar stabilization. The surface energy anisotropy, without regarding the facets, is smaller than that of fcc Al and hcp Co (0.81 $\left.<\frac{\gamma_{\text {tootold }}^{\mathrm{Al}_{13} \mathrm{Co}_{4}}}{\gamma_{\text {tenfold }}^{\mathrm{Al} \mathrm{Co}_{4}}}<1.11\right) .{ }^{66,67}$ Focusing on the facets $\left(\mathrm{M}_{3.15}\right.$ model), they turn up to be the most stable in the full range of allowed chemical potentials, with surface energies ranging from $1.19 \mathrm{~J} / \mathrm{m}^{2}$ (Co-rich potentials) to 1.31 $\mathrm{J} / \mathrm{m}^{2}$ (Al-rich potentials). Thus, they substantially contribute to stabilize the pseudo-twofold orientation over the pseudo-tenfold one.
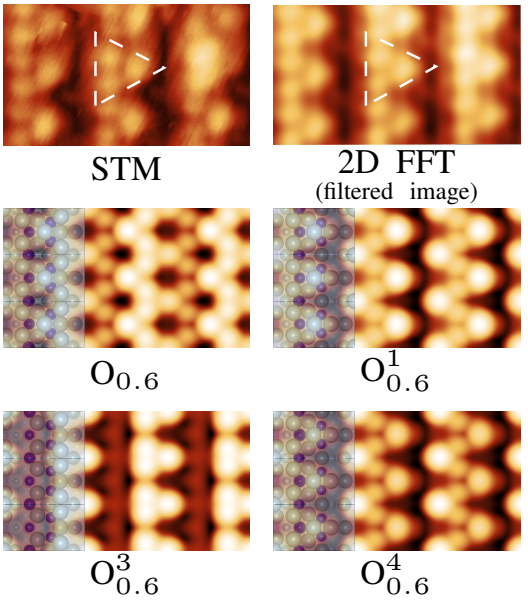

2D FFT

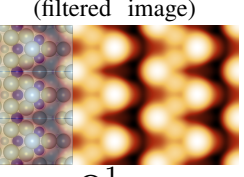

$\mathrm{O}_{0.6}^{1}$

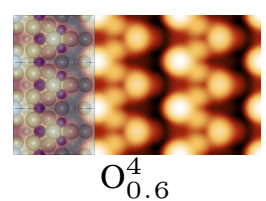

$\mathrm{O}_{0.6}^{4}$

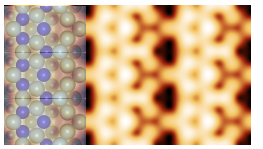

$\mathrm{O}_{1.2}$

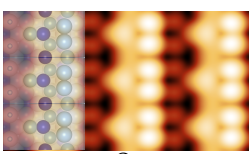

$\mathrm{O}_{1.2}^{3}$

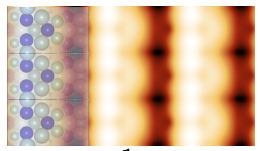

$\mathrm{O}_{1.2}^{1}$

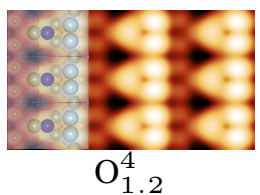

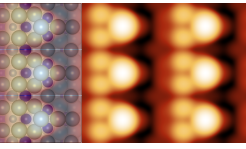

$\mathrm{O}_{0}$
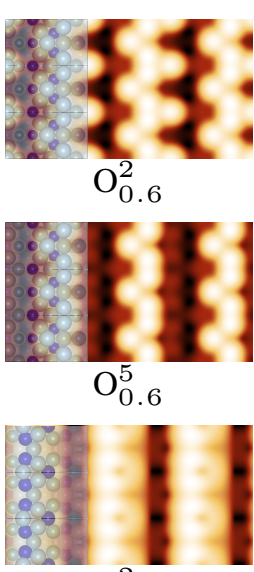

$\mathrm{O}_{1.2}^{2}$

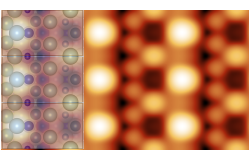

$\mathrm{O}_{5.7}$
Figure 9: STM image simulations (models $\mathrm{O}_{0}, \mathrm{O}_{0.6}, \mathrm{O}_{1.2}$ and $\left.\mathrm{O}_{5.7}\right)$ and comparison to experimental images $\left(\mathrm{V}_{\mathrm{b}}=\right.$ $0.6 \mathrm{~V}, 4.3 \times 2.45 \mathrm{~nm}^{2}$ area $(3 \times 3$ surface cells $\left.)\right)$. 

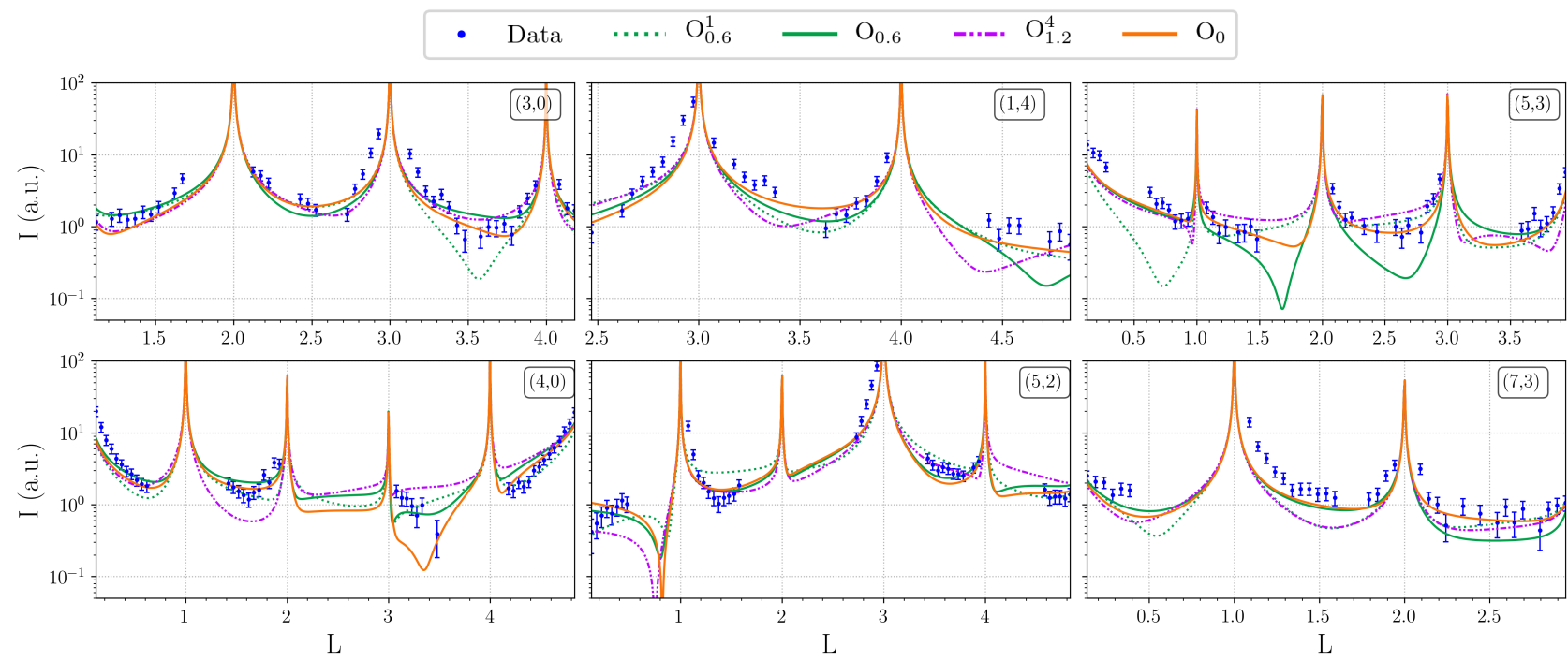

Figure 10: Example of six extracted CTRs of $o-\mathrm{Al}_{13} \mathrm{Co}_{4}(010)$ and their related DFT-based ROD simulation.

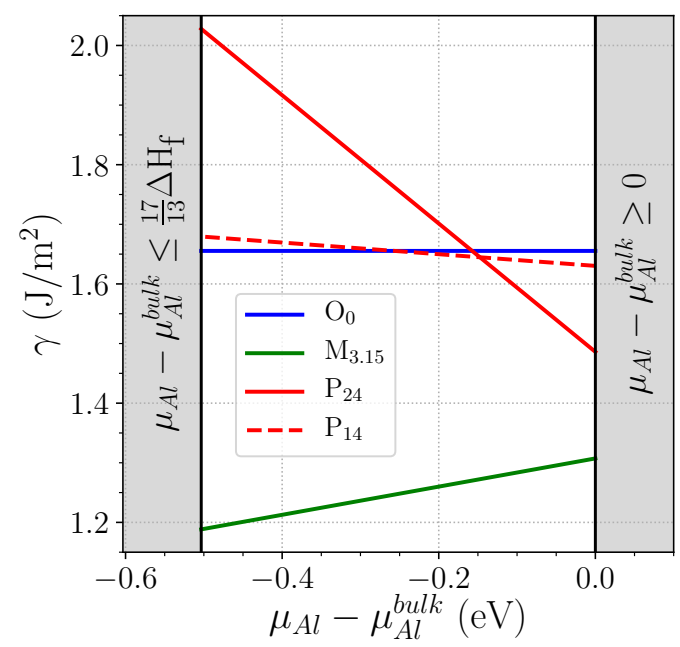

Figure 11: Comparison of $o-\mathrm{Al}_{13} \mathrm{Co}_{4}(100)$ (models $\mathrm{P}_{24}$ and $\left.\mathrm{P}_{14}\right), o-\mathrm{Al}_{13} \mathrm{Co}_{4}(010)$ (model $\left.\mathrm{O}_{0}\right)$ and $m-\mathrm{Al}_{13} \mathrm{Co}_{4}(\overline{2} 01)$ (model $\mathrm{M}_{3.15}$ ) surface energies as a function of $\mu_{A l}-\mu_{A l}^{b u l k}$. 
model $\left(E_{a d s}>-0.58 \mathrm{eV}\right)$, the more stable sites being located on top of the Al "glue" atoms that connects the bipentagonal $\mathrm{Al}$ motif, or in the vicinity of protruding Co atoms. On both surface models, favorable hydrogen adsorption sites remain poorly connected.

The picture is slightly different on the pseudo-twofold surface. Atomic hydrogen is found to be strongly bound to the surface, either on top of $\mathrm{Al}$ atoms located above subsurface Co atoms $\left(\mathrm{O}_{0}\right.$ model, $\left.E_{a d s}>-0.59 \mathrm{eV}\right)$ or on top of Co atoms $\left(\mathrm{M}_{3.15}\right.$ model, $\left.E_{a d s}>-0.53 \mathrm{eV}\right)$. This suggests that hydrogen dissociation is likely on this surface. Additional favorable adsorption sites are found on top or in the vicinity of surface Co atoms, but with weaker adsorption energies, i.e. likely active for hydrogenation steps. All these sites are well connected to one another and it is reasonable to assume that the diffusion of hydrogen atoms on this surface is facilitated. Thus, the comparison of the hydrogen adsorption potential energy maps gives helpful insights to understand the better catalytic performances of the pseudo-twofold surface compared to the pseudo-tenfold one.

\section{Conclusion}

The structure, stability and hydrogen adsorption properties of the $\mathrm{Al}_{13} \mathrm{Co}_{4}$ pseudo-twofold surface have been investigated by a combination of experimental (LEED, AFM, STM and SXRD) and theoretical (DFT calculations) techniques. A highly faceted surface morphology, has been identified, similar to that of the $d$-AlNi-Co (12110) and (10000) twofold quasicrystalline surfaces. Our surface model consists in a coexistence of both flat terraces $\left(o-\mathrm{Al}_{13} \mathrm{Co}_{4}(010)\right)$, made of rows of triangular $\mathrm{Al}_{3}$ motifs separated by a $0.65 \mathrm{~nm}$ gap, and facets $\left(m-\mathrm{Al}_{13} \mathrm{Co}_{4}(\overline{2} 01)\right)$, with a fairly denser and $\mathrm{Co}-$ enriched atomic surface structure. The strong $\mathrm{Co}-\mathrm{Al}-$ Co covalent-like molecular group identified in the bulk is kept intact at the surface in both terraces and facets.

The pseudo-twofold $\mathrm{Al}_{13} \mathrm{Co}_{4}$ surface is calculated to be less stable than the pseudo-tenfold surface in the $\mathrm{Al}$ rich limit $\left(1.66 \mathrm{~J} / \mathrm{m}^{2}\right.$ vs $1.49 \mathrm{~J} / \mathrm{m}^{2}$ for $\left.\mu_{\mathrm{Al}}=\mu_{\mathrm{Al}}^{\text {bulk }}\right)$, while both orientations present similar surface energies in the Al-rich region (1.66-1.68 J/ $\left.\mathrm{m}^{2}\right)$. Without regarding the facets, the surface energy anisotropy is smaller than that of $f c c \mathrm{Al}$ and $h c p$ Co $\left(0.81<\frac{\gamma_{\text {twoofold }}^{\mathrm{Al}_{13} \mathrm{Co}_{4}}}{\gamma_{\text {tenfold }}^{\mathrm{Al} \mathrm{CO}_{4}}}<\right.$ 1.11). ${ }^{66,67}$ Facets substantially stabilize the pseudotwofold surface orientation. Their surface energies are indeed calculated to be much lower than the previous ones $\left(\left[1.19 \mathrm{~J} / \mathrm{m}^{2}: 1.31 \mathrm{~J} / \mathrm{m}^{2}\right]\right)$.

Based on our surface model for the pseudo-twofold surface structure, potential energy maps for atomic hydrogen adsorption have been built. They show a wide diversity of favorable atomic hydrogen adsorption sites, some of them being quite strongly bound to the surface $\left(-0.60<E_{a d s}(\mathrm{H})<-0.50 \mathrm{eV}\right)$, thus likely promoting $\mathrm{H}_{2}$ dissociation, while others interact more weakly with the surface, and are possibly more active for hydrogenation
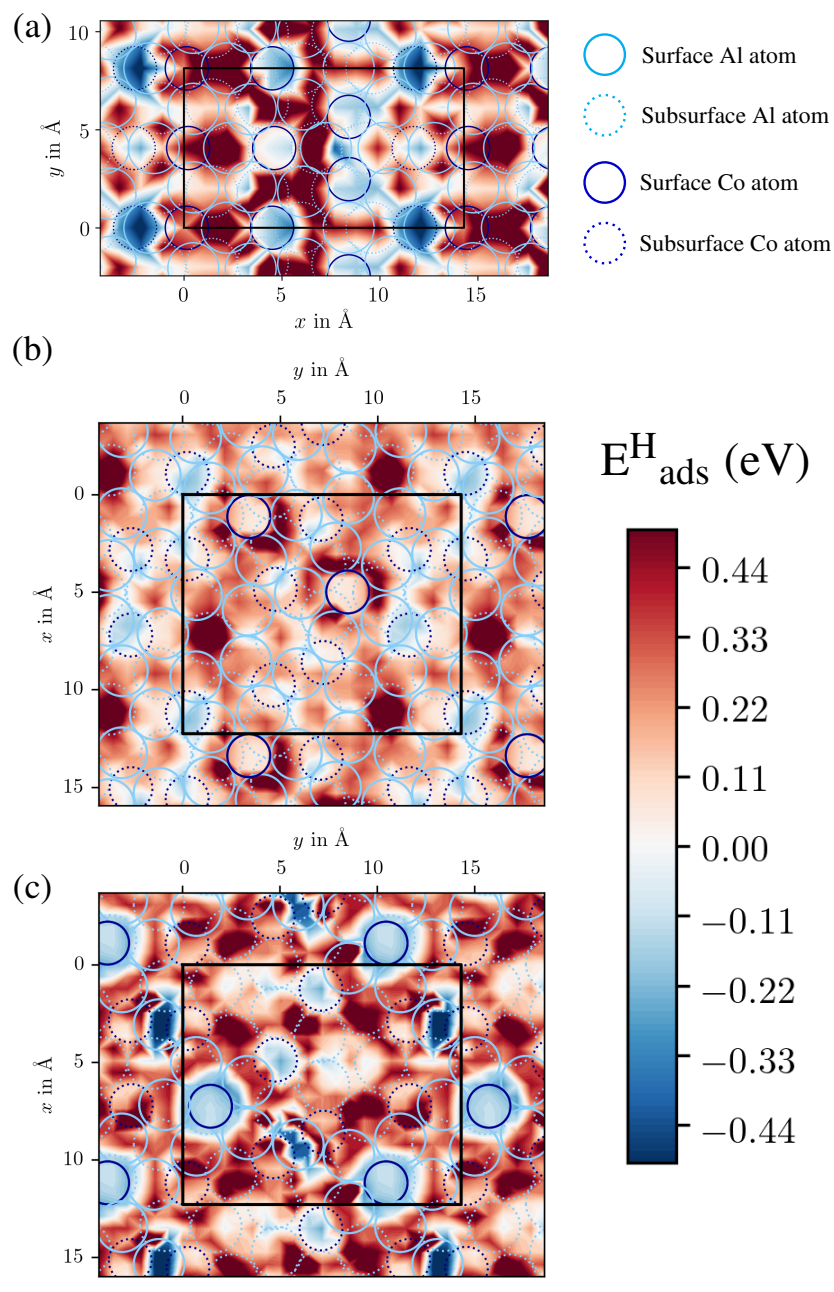

(d)

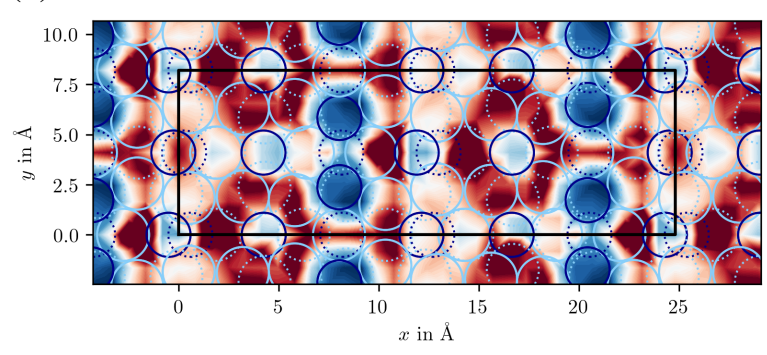

Figure 12: Adsorption energy maps of monoatomic hydrogen on (a) o- $\mathrm{Al}_{13} \mathrm{Co}_{4}(010)$ model $\mathrm{O}_{0}$, (b) o- $\mathrm{Al}_{13} \mathrm{Co}_{4}(100)$ model $\mathrm{P}_{24}$, (c) $o-\mathrm{Al}_{13} \mathrm{Co}_{4}(100)$ model $\mathrm{P}_{14}$ and (d) $m-\mathrm{Al}_{13} \mathrm{Co}_{4}(\overline{2} 01)$ model $\mathrm{M}_{3.15}$. 
steps. As already predicted for the pseudo-tenfold orientation, ${ }^{35}$ reaction conditions may modify the faceted structure of the pseudo-twofold surface identified under ultra-high vacuum conditions. Further experimental and theoretical works - under catalytic conditions are therefore needed to fully understand the mechanism behind the catalytic properties of $\mathrm{O}-\mathrm{Al}_{13} \mathrm{Co}_{4}(010)$.

Acknowledgement C.C. acknowledges Synchrotron SOLEIL and Région Grand Est for financial support. The authors thank Benjamin Voisin for technical support throughout the SXRD experiments and Dr. Michèle Sauvage-Simkin for fruitful discussions. The authors also thank Dr. S. Kubsky, F. Nicolas and A. Loncle from SOLEIL Surface Laboratory for providing AFM equipment and support. This work is supported by the European Integrated Center for the Development of New Metallic Alloys and Compounds. E.G. acknowledge financial support through the COMETE project (COnception in silico de Matériaux pour l'EnvironnemenT et l'Énergie) cofunded by the European Union under the program FEDER-FSE Lorraine et Massif des Vosges 2014-2020. This work was granted access to the HPC resources of TGCC, CINES and IDRIS under the allocation 99642 attributed by GENCI (Grand Equipement National de Calcul Intensif). High Performance Computing resources were also partially provided by the EXPLOR centre hosted by the University de Lorraine (project 2017M4XXX0108).

\section{Supporting Information Available}

Twins and metadislocations in $\mathrm{Al}_{13} \mathrm{Co}_{4} ; o-\mathrm{Al}_{13} \mathrm{Co}_{4}(100)$ surface models $\left(\mathrm{P}_{14}\right.$ and $\left.\mathrm{P}_{24}\right)$; Relaxed $\mathrm{Al}_{13} \mathrm{Co}_{4}$ bulk structures; LEED-AFM-STM; $o-\mathrm{Al}_{13} \mathrm{Co}_{4}(010)$ and $m$ $\mathrm{Al}_{13} \mathrm{Co}_{4}(\overline{2} 01)$ surface models $\left(\mathrm{O}_{0}\right.$ and $\left.\mathrm{M}_{3.15}\right)$

\section{References}

(1) Shechtman, D.; Blech, I.; Gratias, D.; Cahn, J. Metallic Phase with Long-Range Orientational Order and No Translational Symmetry. Phys. Rev. Lett. 1984, 53, 1951-1953.

(2) Dubois, J. M. Properties and Applications of Quasicrystals and Complex Metallic Alloys . Chem. Soc. Rev. 2012, 41, 6760-6777.

(3) Belin-Ferré, E., Ed. Properties and Applications of Complex Intermetallics; World Scientific Publishing: Singapore, 2008.

(4) Roche, S.; de Laissardière, G. T.; Mayou, D. Electronic Transport Properties of Quasicrystals. J. Math. Phys. 1997, 38, 1794.

(5) Ahn, S. J.; Moon, P.; Kim, T.-H.; Kim, H.-W.; Shin, H.-C.; Kim, E. H.; Cha, H. W.; Kahng, S.J.; Kim, P.; Koshino, M. et al. Dirac Electrons in a Dodecagonal Graphene Quasicrystal. Science 2018, 361, 782-786.

(6) Jeon, S.; Kwon, H.; Hur, K. Intrinsic Photonic Wave Localization in a Three-Dimensional Icosahedral Quasicrystal. Nat. Phys. 2017, 13, 363368.

(7) Thiel, P. Quasicrystal Surfaces. Annu. Rev. Phys. Chem. 2008, 59, 129.

(8) Sharma, H.; Fournée, V.; Shimoda, M.; Ross, A.; Lograsso, T.; Tsai, A.; Yamamoto, A. Structure of the Fivefold Surface of the Icosahedral Al-CuFe Quasicrystal: Experimental Evidence of Bulk Truncations at Larger Interlayer Spacings. Phys. Rev. Lett. 2004, 93, 165502-1.

(9) Papadopolos, Z.; Kasner, G.; Ledieu, J.; Cox, E. J.; Richardson, N. V.; Chen, Q.; Diehl, R. D.; Lograsso, T. A.; Ross, A. R.; McGrath, R. Bulk Termination of the Quasicrystalline Fivefold Surface of $\mathrm{Al}_{70} \mathrm{Pd}_{21} \mathrm{Mn}_{9}$. Phys. Rev. B 2002, 88, 184207.

(10) Sharma, H.; Shimoda, M.; Sagisaka, K.; Takakura, H.; Smerdon, J.; Nugent, P.; Mcgrath, R.; Fujita, D.; Ohhashi, S.; Tsai, A. Structure of the Fivefold Surface of the Ag-In-Yb Icosahedral Quasicrystal. Phys. Rev. B 2009, 80, 121401.

(11) Ledieu, J.; Fournée, V. Surfaces of quasicrystals. C. R. Physique 2014, 15, 48-57.

(12) Shen, Z.; Raberg, W.; Heinzig, M.; Jenks, C.; Fournée, V.; Van-Hove, M.; Lograsso, T.; Delaney, D.; Cai, T.; Canfield, P. et al. A LEED Comparison of Structural Stabilities of the Three High-Symmetry Surfaces of Al-Pd-Mn Bulk Quasicrystals. Surf. Scie. 2000, 450, 1-11.

(13) Shen, Z.; Jenks, C.; Anderegg, J.; Delaney, D. W.; Lograsso, T. A.; Thiel, P.; Goldman, A. Structure and Stability of the Twofold Surface of Icosahedral Al-Pd-Mn by Low-Energy Electron Diffraction and X-Ray Photoemission Spectroscopy. Phys. Rev. Lett. 1997, 78, 1050-1053.

(14) Kluge, F.; Yurechko, M.; Urban, K.; Ebert, P. Influence of Growth Kinetics and Chemical Composition on the Shape of Voids in Quasi-Crystals. Surf. Sci. 2002, 519, 33-39.

(15) Cui, C.; Nugent, P. J.; Shimoda, M.; Ledieu, J.; Fournée, V.; Tsai, A. P.; McGrath, R.; Sharma, H. R. Structure of the Twofold Surface of the Icosahedral Ag-In-Yb Quasicrystal. J. Phys.: Condens. Matter 2014, 26, 015001. 
(16) Tamura, R.; Yadav, T.; McLeod, I.; Hesp, D.; Young, K.; Nakamura, T.; Nishio, K.; Dhanak, V.; McGrath, R.; Sharma, H. Scanning Tunneling Microscopy of a Polygrain Al-Pd-Re Quasicrystal: Study of the Relative Surface Stability. J. Phys.: Condens. Matter 2013, 25, 395007.

(17) Mader, R.; Widmer, R.; Groning, P.; Deloudi, S.; Steurer, W.; Heggen, M.; Schall, P.; Feuerbacher, M.; Groning, O. High-Resolution Scanning Tunneling Microscopy Investigation of the (12110) and (10000) Two-Fold Symmetric d-Al-NiCo Quasicrystalline Surfaces. Phys. Rev. B 2009, $80,035433$.

(18) Duguet, T.; Unal, B.; de Weerd, M. C.; Ledieu, J.; Ribeiro, R. A.; Canfield, P. C.; Deloudi, S.; Steurer, W.; Jenks, C. J.; Dubois, J. M. et al. Twofold Surface of the Decagonal Al-Cu-Co Quasicrystal. Phys. Rev. B 2009, 80, 024201.

(19) Krajčí, M.; Hafner, J. Structure, Stability and Electronic Properties of the i-AlPdMn Quasicristalline Surface. Phys. Rev. B 2005, 71, 054202.

(20) Krajčí, M.; Hafner, J.; Ledieu, J.; McGrath, R. Surface Vacancies at the Fivefold Icosahedral AlPd-Mn Quasicrystal Surface: A Comparison of Ab Initio Calculated and Experimental STM Images. Phys. Rev. B 2006, 73, 024202.

(21) Krajčí, M.; ; Hafner, J.; Mihalkovič, M. Ab initio study of the surface of a decagonal Al-Co-Ni quasicrystal. Phys. Rev. B 2006, 73, 134203.

(22) Franke, K.; Sharma, H.; Theis, W.; Gille, P.; Ebert, P.; Rieder, K. Quasicrystalline Epitaxial Single Element Monolayers on Icosahedral Al-PdMn and Decagonal Al-Ni-Co Quasicrystal Surfaces. Phys. Rev. Lett. 2002, 89, 156104.

(23) Sharma, H. R.; Nozawa, K.; Smerdon, J. A.; Nugent, P. J.; McLeod, I.; Dhanak, V. R.; Shimoda, M.; Ishii, Y.; Tsai, A. P.; McGrath, R. Templated Three-Dimensional Growth of Quasicrystalline Lead. Nat. Commun. 2013, 4, 2715.

(24) Krajčí, M.; Hafner, J. Complex Intermetallic Compounds as Selective Hydrogenation Catalysts - A Case Study for the (100) Surface of $\mathrm{Al}_{13} \mathrm{Co}_{4} . J$. Catal. 2011, 278, 200-207.

(25) Krajčí, M.; Hafner, J. The (210) Surface of Intermetallic B20 Compound GaPd as a Selective Hydrogenation Catalyst: a DFT Study. J. Catal. 2012, 295, 70-80.

(26) Krajci, M.; Hafner, J. Surfaces of Intermetallic Compounds: an Ab Initio DFT Study for B20Type AlPd. Phys. Rev. B 2013, 87, 035436.
(27) Armbrüster, M.; Kovnir, K.; Friedrich, M.; Teschner, D.; Wowsnick, G.; Hahne, M.; Gille, P.; Szentmiklosi, L.; Feuerbacher, M.; Heggen, M. et al. $\mathrm{Al}_{13} \mathrm{Fe}_{4}$ as a Low-Cost Alternative for Palladium in Heterogeneous Hydrogenation. Nat. Mater. 2012, 11, 690-693.

(28) Piccolo, L. $\mathrm{Al}_{13} \mathrm{Fe}_{4}$ Selectively Catalyzes the Hydrogenation of Butadiene At Room Temperature. Chem. Commun. 2013, 49, 9149-9151.

(29) Piccolo, L.; Kibis, L. The Partial Hydrogenation of Butadiene over $\mathrm{Al}_{13} \mathrm{Fe}_{4}$ : A Surface-Science Study of Reaction and Deactivation Mechanisms. J. Catal. 2015, 332, 112.

(30) Piccolo, L.; Chatelier, C.; de Weerd, M.-C.; Morfin, F.; Ledieu, J.; Fournée, V.; Gille, P.; Gaudry, E. Catalytic Properties of $\mathrm{Al}_{13} \mathrm{TM}_{4}$ Complex Intermetallics: Influence of the Transition Metal and the Surface Orientation On Butadiene Hydrogenation. Sci. Tech. Adv. Mater. 2019, 20, $557-567$.

(31) Addou, R.; Gaudry, É.; Deniozou, T.; Heggen, M.; Feuerbacher, M.; Gille, P.; Grin, Y.; Widmer, R.; Groening, O.; Fournée, V. et al. Investigation of the (100) Surface of the Orthorhombic $\mathrm{Al}_{13} \mathrm{Co}_{4}$ Crystal. Phys. Rev. B 2009, 80, 014203.

(32) Shin, H.; Pussi, K.; Gaudry, É.; Ledieu, J.; Fournée, V.; Alarcón-Villaseca, S.; Dubois, J.-M.; Grin, Y.; Gille, P.; Moritz, W. et al. Structure of the Orthorhombic $\mathrm{Al}_{13} \mathrm{Co}_{4}(100)$ Surface Using LEED, STM and Ab Initio Studies. Phys. Rev. B 2011, 84, 085411 (1to11).

(33) Ledieu, J.; Gaudry, E.; de Weerd, M.-C.; Diehl, R. D.; Fournée, V. The (100) Surface of the $\mathrm{Al}_{13} \mathrm{Co}_{4}$ Quasicrystalline Approximant. Mater. Res. Soc. Symp. Proc. 2012, 1517.

(34) Gaudry, E.; Chatelier, C.; McGuirk, G.; Loli, L. S.; DeWeerd, M.-C.; Ledieu, J.; Fournée, V.; Felici, R.; Drnec, J.; Beutier, G. et al. Structure of the $\mathrm{Al}_{13} \mathrm{Co}_{4}(100)$ Surface: Combination of Surface X-Ray Diffraction and Ab Initio Calculations. Phys. Rev. B 2016, 94, 165406.

(35) Gaudry, E.; Chatelier, C.; Loffreda, D.; Kandaskalov, D.; Coati, A.; Piccolo, L. Catalytic activation of a non-noble intermetallic surface through nanostructuration under hydrogenation conditions revealed by atomistic thermodynamics. J. Mater. Chem. A 2020, 8, 7422-7431.

(36) Priputen, P.; Kusý, M.; Drienovský, M.; Janičkovič, D.; Čička, R.; Černičková, I.; Janovec, J. Experimental Reinvestigation of AlâĂŞCo Phase Diagram in Vicinity of $\mathrm{Al}_{13} \mathrm{Co}_{4}$ 
Family of Phases. J. Alloys Compd. 2015, 647, 486-497.

(37) Grin, J.; Burkhardt, U.; Ellner, M.; Peters, K. Crystal Structure of Orthorhombic $\mathrm{Co}_{4} \mathrm{Al}_{13} . \mathrm{J}$. Alloys Compd. 1994, 206, 243-247.

(38) Burkhardt, U.; Ellner, M.; Grin, Y.; Baumgartner, B. Powder Diffraction Refinement of the $\mathrm{Co}_{2} \mathrm{Al}_{5}$ Structure. Powder Diffr. 1998, 13, 159 162 .

(39) Mihalkovič, M.; Widom, M. First-Principles Calculations of Cohesive Energies In the Al-Co Binary Alloy System. Phys. Rev. B 2007, 75, 014207.

(40) Hudd, R.; Taylor, W. The Structure of $\mathrm{Co}_{4} \mathrm{Al}_{13}$. Acta Cryst. A 1962, 15, 441.

(41) Feuerbacher, M.; Heggen, M. On the Concept of Metadislocations in Complex Metallic Alloys. Philos. Mag. 2006, 86, 935-944.

(42) Heggen, M.; Houben, L.; Feuerbacher, M. Metadislocations in the Structurally Complex Orthorhombic Alloy $\mathrm{Al}_{13} \mathrm{Co}_{4}$. Philos. Mag. 2008, 88, 2333-2338.

(43) Heggen, M.; Houben, L.; Feuerbacher, M. PlasticDeformation Mechanism in Complex Solids. Nat. Mater. 2010, 9, 332-336.

(44) Heidelmann, M.; Heggen, M.; Dwyer, C.; Feuerbacher, M. Comprehensive Model of Metadislocation Movement in $\mathrm{Al}_{13} \mathrm{Co}_{4}$. Scr. Mater. 2015, 98 .

(45) Saito, K.; Sugiyama, K.; Hiraga, K. $\mathrm{Al}_{13} \mathrm{M}_{4}$-type Structures and Atomic Models of their Twins. Mater. Sci. Eng. A 2000, 294-296, 279-282.

(46) Scheid, P.; Chatelier, C.; Ledieu, J.; Fournée, V.; Gaudry, E. Bonding Network and Stability of Clusters: The Case Study of the $\mathrm{Al}_{13} \mathrm{TM}_{4}$ Pseudo10fold Surfaces. Acta Crystallogr. A 2019, 75, $314-324$.

(47) Jeglic, P.; Vrtnik, S.; Bobnar, M.; Klanjsek, M.; Bauer, B.; Gille, P.; Grin, Y.; Haarmann, F.; Dolinsek, J. M-Al-M Groups Trapped in Cages of $\mathrm{Al}_{13} \mathrm{M}_{4}(\mathrm{M}=\mathrm{Co}, \mathrm{Fe}, \mathrm{Ni}, \mathrm{Ru})$ Complex Intermetallic Phases as Seen via NMR. Phys. Rev. B 2010, 82, 104201.

(48) Vlieg, E. Integrated Intensities Using A Six-Circle Surface X-Ray Diffractometer. J. Appl. Cryst 1997, 30, 532-543.

(49) Robach, O.; Garreau, Y.; Aïd, K.; VéronJolliot, M. B. Corrections for Surface X-Ray Diffraction Measurements Using the Z-Axis Geometry: Finite Size Effects in Direct and Reciprocal Space. J. Appl. Cryst. 2000, 33, 1006-1018.
(50) Drnec, J.; Zhou, T.; Pintea, S.; Onderwaater, W.; Vlieg, E.; Renaud, G.; Felici, R. Integration Techniques for Surface X-Ray Diffraction Data Obtained With A Two-Dimensional Detector. J. Appl. Cryst. 2014, 4\%, 365-377.

(51) Roobol, S.; Onderwaater, W.; Drnec, J.; Felici, R.; Frenken, J. BINoculars : Data Reduction and Analysis Software for Two-Dimensional Detectors in Surface X-Ray Diffraction. J. Appl. Cryst. 2015, 48, 1324-1329.

(52) Vlieg, E. ROD: A Program for Surface X-Ray Crystallography. J. Appl. Cryst 2000, 33, 401405.

(53) Kresse, G.; Furthmüller, J. Efficient Iterative Schemes for Ab Initio Total-Energy Calculations Using A Plane-Wave Basis Set. Phys. Rev. B 1996, 54, $11169-11186$.

(54) Blochl, P. E. Projector Augmented-Wave Method. Phys. Rev. B 1994, 50, 17953-17979.

(55) Kresse, G.; Joubert, D. From Ultrasoft Pseudopotentials To the Projector Augmented-Wave Method. Phys. Rev. B 1999, 59, 1758-1775.

(56) Perdew, J. P.; Burke, K.; Ernzerhof, M. Generalized Gradient Approximation Made Simple . Phys. Rev. Lett. 1996, 77, 3865.

(57) Grimme, S.; Antony, J.; Ehrlich, S.; Krieg, H. A Consistent and Accurate Ab Initio Parametrization of Density Functional Dispersion Correction (DFT-D) for the 94 Elements H-Pu. J. Chem. Phys. 2010, 132, 154104.

(58) Patra, A.; Bates, J. E.; Sun, J.; Perdew, J. P. Properties of Real Metallic Surfaces: Effects of Density Functional Semilocality and Van der Waals Nonlocality. PNAS 2017, 114, E91.

(59) Momma, K.; Izumi, F. VESTA 3 for ThreeDimensional Visualization of Crystal, Volumetric and Morphology Data. J. Appl. Crystallogr. 2011, 44, 1272-1276.

(60) Fleischer, F.; Weber, T.; Jung, D. Y.; Steurer, W. o'- $\mathrm{Al}_{13} \mathrm{Co}_{4}$, a New Quasicrystal Approximant. J. Alloys Compd. 2010, 500, 153-160.

(61) Tersoff, J.; Hamann, D. R. Theory and Application for the Scanning Tunneling Microscope. Phys. Rev. Lett. 1983, 50, 1998-2001.

(62) Reuter, K.; Stampfl, C.; Ganduglia-Pirovano, M.; Scheffler, M. Atomistic Description of Oxide Formation on Metal Surfaces: the Example of Ruthenium . Chem. Phys. Letters 2002, 352, 311. 
(63) Reuter, K.; Scheffler, M. Composition and Structure of the $\mathrm{RuO}_{2}(110)$ Surface in an $\mathrm{O}_{2}$ and $\mathrm{CO}$ Environment: Implications for the Catalytic Formation of $\mathrm{CO}_{2}$. Phys. Rev. B 2003, 68, 045407.

(64) Chatelier, C.; Garreau, Y.; Piccolo, L.; Vlad, A.; Resta, A.; Ledieu, J.; Fournée, V.; deWeerd, M.C.; Picca, F.-E.; deBoissieu, M. et al. From the Surface Structure to Catalytic Properties of $\mathrm{Al}_{5} \mathrm{Co}_{2}(2-10)$ : A Study Combining Experimental and Theoretical Approaches. J. Phys. Chem. C 2020, 124, 4552-4562.

(65) Bechstedt, F. Principles of Surface Physics; Springer: Berlin, 2003.

(66) Vitos, L.; Ruban, A.; Skriver, H.; Kollár, J. The Surface Energy of Metals. Surf. Sci. 1998, 411, 186.

(67) Tran, R.; Xu, Z.; Radhakrishnan, B.; Winston, D.; Sun, W.; Persson, K.; Ping-Ong, S. Surface Energies of Elemental Crystals. Scientific Data 2016, 3, 160080 .

(68) Kandaskalov, D.; Fournée, V.; Ledieu, J.; Gaudry, E. Catalytic Semihydrogenation of Acetylene on the (100) Surface of the o- $\mathrm{Al}_{13} \mathrm{Co}_{4}$ Quasicrystalline Approximant: Density Functional Theory Study. J. Phys. Chem. C 2017, 121, 18738-18745.

TOC Graphic
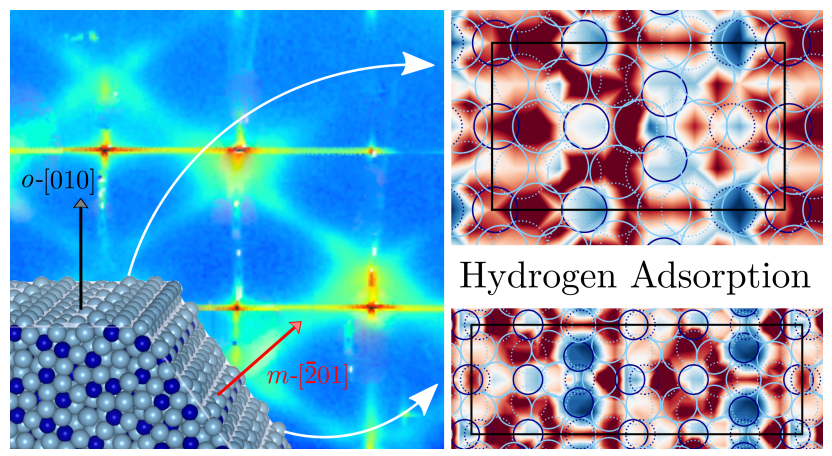


\title{
The pseudo-twofold surface of the $\mathrm{Al}_{13} \mathrm{Co}_{4}$ catalyst: structure, stability, and hydrogen adsorption
}

\author{
Corentin Chatelier ${ }^{1,2}$, Yves Garreau ${ }^{2,3}$, Alina Vlad ${ }^{2}$, Julian Ledieu$^{1}$, Andrea Resta ${ }^{2}$, \\ Vincent Fournée ${ }^{1}$, Marie-Cécile de Weerd ${ }^{1}$, Alessandro Coati*,2 and Émilie Gaudry,1 \\ ${ }^{1}$ Université de Lorraine, CNRS, Institut Jean Lamour - UMR 7198, F-54011, Nancy, France \\ ${ }^{2}$ Synchrotron SOLEIL, L'Orme des Merisiers, Saint-Aubin, BP 48, F-91192 Gif-sur-Yvette Cedex, France \\ ${ }^{3}$ Université de Paris, CNRS, Matériaux et Phénomènes Quantiques - UMR 7162, Paris, France \\ E-mail: alessandro.coati@synchrotron-soleil.fr,emilie.gaudry@univ-lorraine.fr
}

SUPPORTING INFO 


\section{$\mathrm{S} 1$ - Twins and metadislocations in $\mathrm{Al}_{13} \mathrm{Co}_{4}$}

Two main defects are experimentally observed in $\mathrm{Al}_{13} \mathrm{Co}_{4}$. First, twins are generally quite frequent, and orthorhombic/monoclinic interfaces are naturally present in the bulk material ${ }^{1}$ (Fig. S1). Another recurrent defects in complex intermetallic compounds are metadislocations, and appear due to plastic deformations ${ }^{2-4}$ : they are line defects with a Burger vector corresponding to a $\tau^{-n}$-fraction of a lattice constant, with $\tau$ the golden ratio defined by $\tau=\frac{1+\sqrt{5}}{2}$ and $n \in \mathbb{N}^{\star}$. They are related to dislocations, generally affected by phasons, and associated with a region of phase modification, by which the irrational Burgers vector is accommodated in the crystal lattice. ${ }^{5}$

Complementary (and so far unpublished) SXRD analysis on another surface orientation $-o-\mathrm{Al}_{13} \mathrm{Co}_{4}(001)$, using a single crystal also grown by the Czochralski process, shows a similar diffuse scattering in between integer values of H. Fig. S2 displays the same reciprocal space area (yellow rectangle in Fig. 4(a) of the main document) for (a) $o-\mathrm{Al}_{13} \mathrm{Co}_{4}(010)$ and (b) o- $\mathrm{Al}_{13} \mathrm{Co}_{4}(001)$. This section is a plane along the [100] direction at $Q=2.7 \AA^{-1}$. The fact that the diffuse scattering is almost identical in both cases suggests that this signal mainly comes from the bulk material and not from the surface.

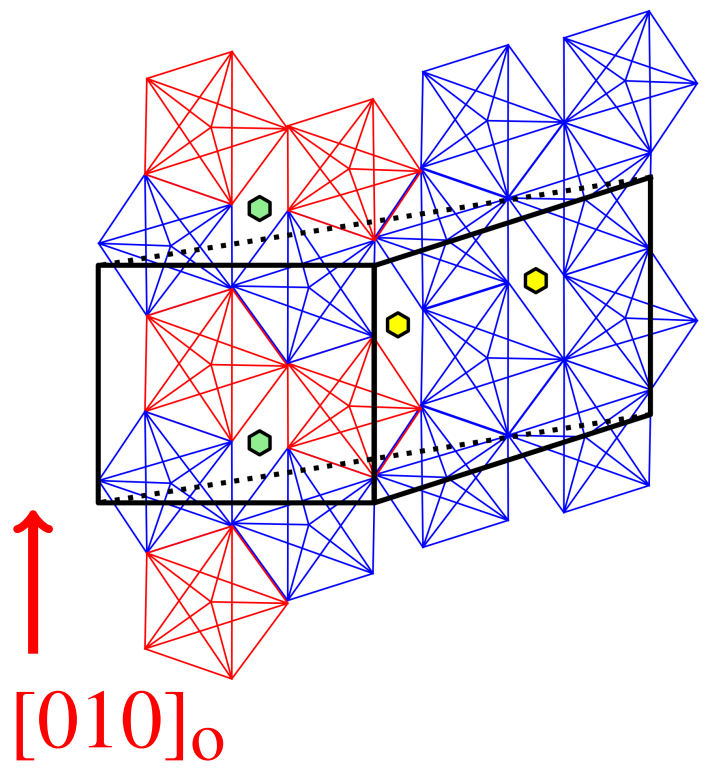

(a)

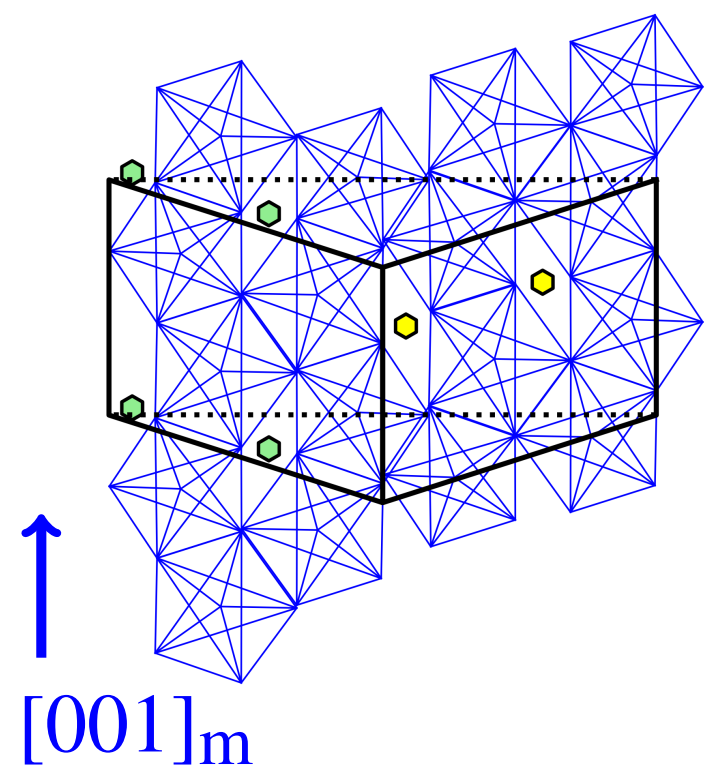

(b)

Figure S1: Structure models of (a) orthorhombic/monoclinic and (b) monoclinic/monoclinic interfaces. Henley clusters are represented with blue and red pentagons; following the same color code as in Fig. 1 of the main document. The orthorhombic and monoclinic cells are drawn in black. The DFT calculation boxes are displayed using dotted black lines. 


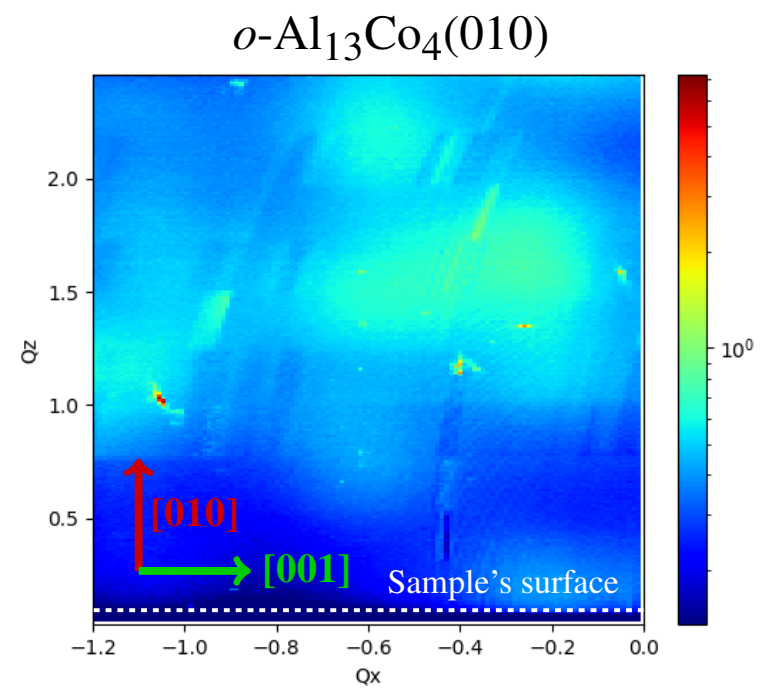

(a)

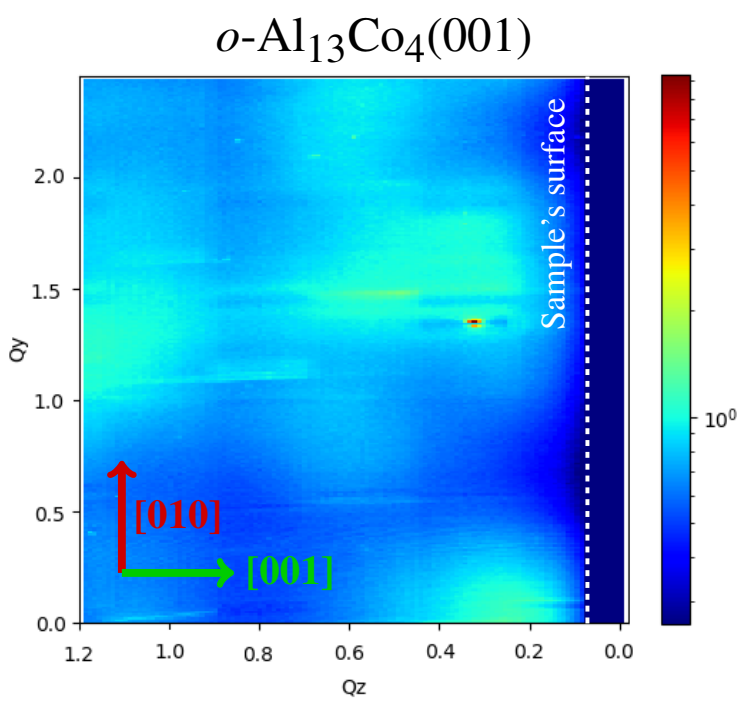

(b)

Figure S2: Portion of out-of-plane reciprocal space map along [100] at $Q=2.7 \AA^{-1}$ for (a) $o-\mathrm{Al}_{13} \mathrm{Co}_{4}(010)$ and (b) for $o-\mathrm{Al}_{13} \mathrm{Co}_{4}(001)$. These two area of the reciprocal space are the same for $o-\mathrm{Al}_{13} \mathrm{Co}_{4}(010)$ and $o-\mathrm{Al}_{13} \mathrm{Co}_{4}(001)$.

The features that are displayed in orange in Fig. 4(b) of the main document can be generated by defects such as dislocations. A simulation of the Fourier transform of a $\mathrm{Al}_{13} \mathrm{Co}_{4}$ metadislocation is done to evaluate this hypothesis. The atomic structure that was used is based on the dislocation model of Heidelmann et al. ${ }^{5}$ and is displayed in Fig. S3(c). The Fourier transform of such defect is shown in Fig. S3(b) and compared to the experimental measurements Fig. S3(a). This kind of diffraction peaks and diffuse scattering might also be generated by periodically stacked phason planes (related to metadislocations). 
(a)

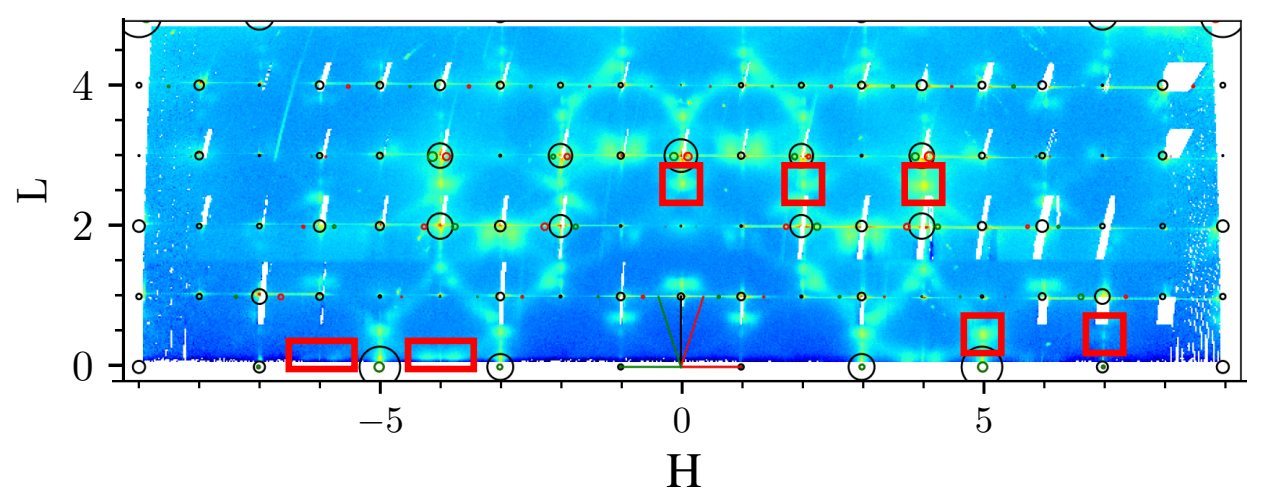

(b)

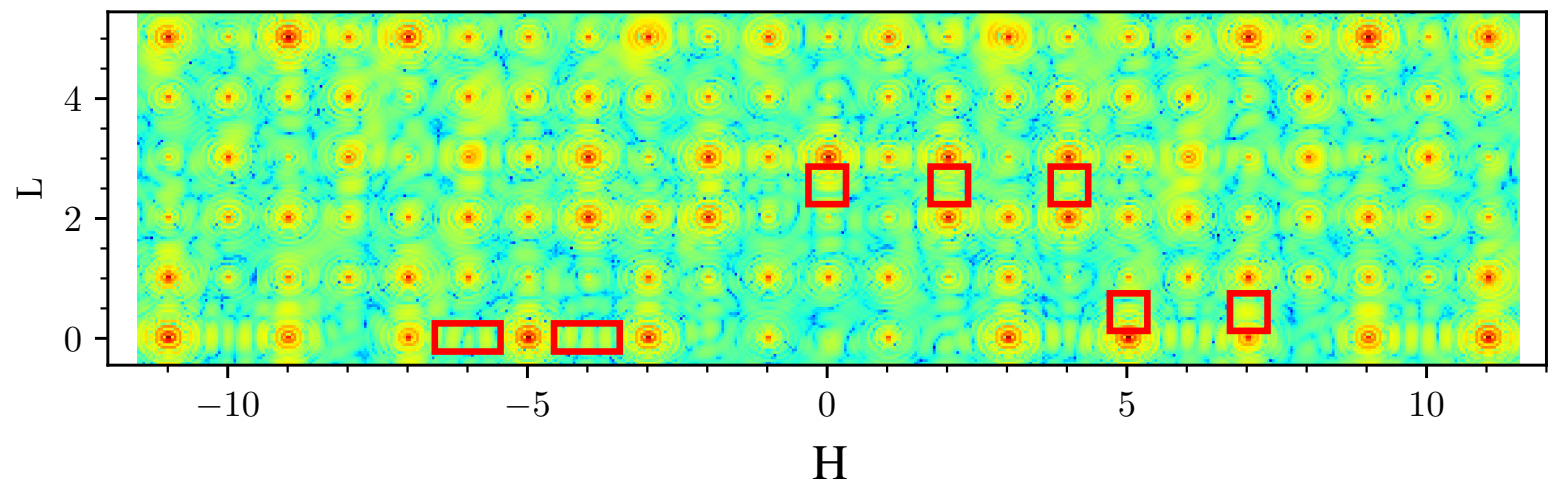

(c)

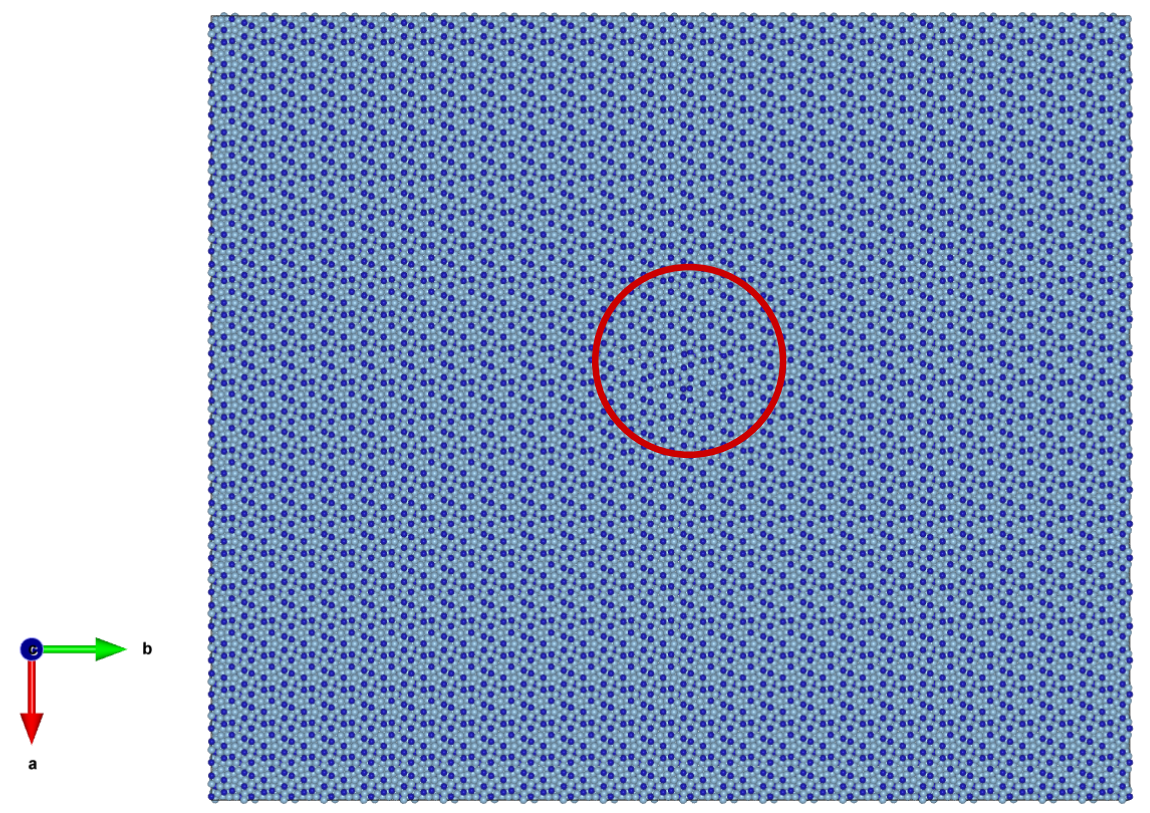

Figure S3: (a) (H,L) out-of-plane reciprocal space maps at $\mathrm{K}=3$ of $o-\mathrm{Al}_{13} \mathrm{Co}_{4}(010)$. (b) Simulated out-of-plane maps at $\mathrm{K}=3$ : FT simulation of a $23 \times 23 \times 1$ orthorhombic cell with a core dislocation in the center of the cell. Features that do not come from the orthorhombic structure are highlighted in red for both figures (a) and (b). Similarities between the measurements and the simulation are observed. (c) Atomic structure of the FT 23x23x1 simulation box : $\mathrm{Al}$ and Co atoms are drawn in light blue and dark blue, respectively; the metadislocation core is circled in red. 
$\mathrm{S} 2-o-\mathrm{Al}_{13} \mathrm{Co}_{4}(100)$ surface models

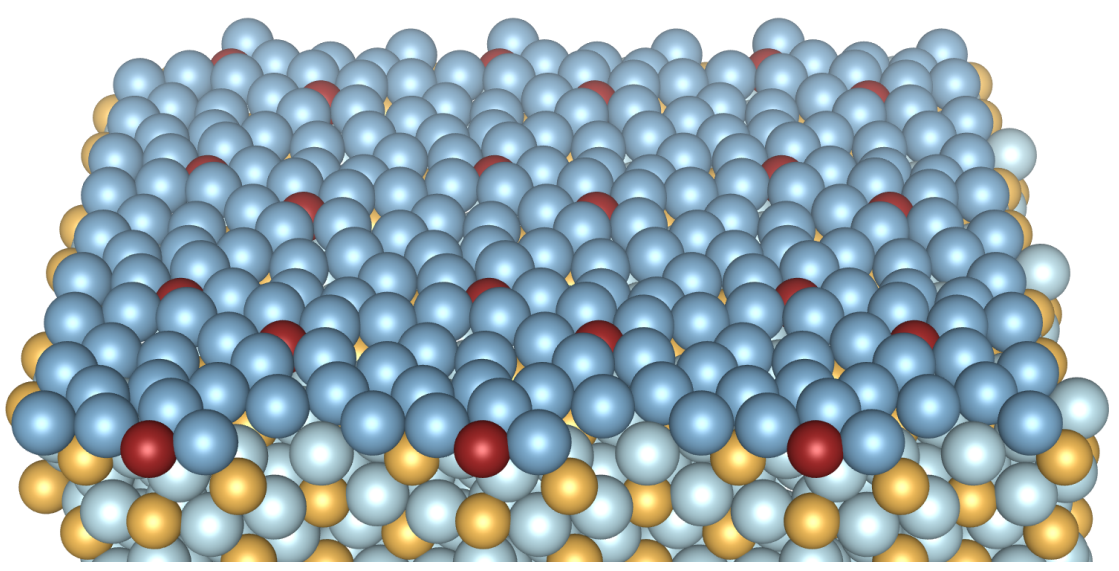

Figure S4: Surface structure of model $\mathrm{P}_{24}$ (flat surface). Surface Al and Co atoms are drawn in blue and red, respectively. Subsurface $\mathrm{Al}$ and Co atoms are drawn in light blue and orange, respectively.

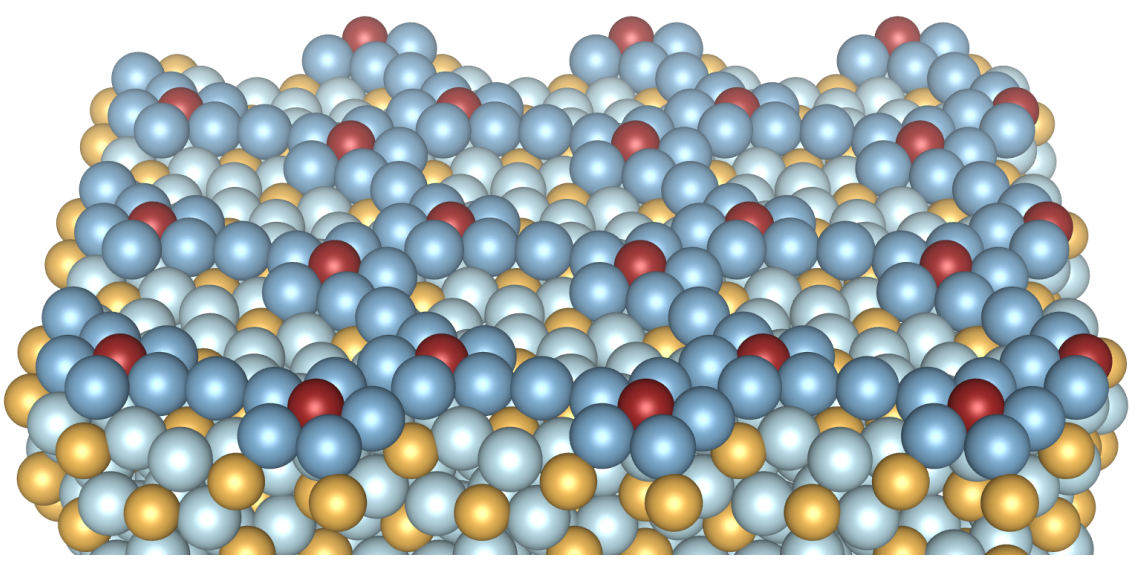

Figure S5: Surface structure of model $\mathrm{P}_{14}$ (nanostructured surface)). Surface Al and Co atoms are drawn in blue and red, respectively. Subsurface $\mathrm{Al}$ and Co atoms are drawn in light blue and orange, respectively. 


\section{$\mathrm{S} 3$ - Relaxed $\mathrm{Al}_{13} \mathrm{Co}_{4}$ bulk structures}

The crystallographic information (equivalent positions and Wyckoff numbers for monoclinic and orthorhombic structures relaxed by DFT) are presented in the following tables. The $\mathrm{Al}$ atoms that are present in the center of the Henley clusters are $\mathbf{A l 1 5}$ for $m-\mathrm{Al}_{13} \mathrm{Co}_{4},{ }^{6} \mathbf{A l 1 6}$ and $\mathbf{A l 1 7}$ for $o-\mathrm{Al}_{13} \mathrm{Co}_{4} \cdot{ }^{7}$

\begin{tabular}{|c|c|c|c|c|c|}
\hline \multicolumn{6}{|c|}{$m$ - $\mathrm{Al}_{13} \mathrm{Co}_{4}(\text { Spage group } \mathrm{C} 2 / \mathrm{m} \text {, group number } 12)^{6}$} \\
\hline \multicolumn{6}{|c|}{ Lattice parameters } \\
\hline $\mathrm{a}$ & $\mathrm{b}$ & $\mathrm{c}$ & alpha & beta & gamma \\
\hline 15.18300 & 8.12200 & 12.34000 & 90.0000 & 107.9000 & 90.0000 \\
\hline \multicolumn{6}{|c|}{ Structure parameters (x,y,z, Wyckoff number and symmetry) } \\
\hline Al11 & 0.13671 & 0.21951 & 0.52149 & $8 \mathrm{j}$ & 1 \\
\hline Al10 & 0.17829 & 0.27988 & 0.33435 & $8 \mathrm{j}$ & 1 \\
\hline Al7 & 0.18555 & 0.28240 & 0.11092 & $8 \mathrm{j}$ & 1 \\
\hline $\mathrm{Co} 5$ & 0.31973 & 0.20658 & 0.27779 & $8 \mathrm{j}$ & 1 \\
\hline Al13 & 0.36793 & 0.28805 & 0.10985 & $8 \mathrm{j}$ & 1 \\
\hline Al14 & 0.49182 & 0.26717 & 0.32987 & $8 \mathrm{j}$ & 1 \\
\hline $\mathrm{Al} 4$ & 0.02071 & 0.00000 & 0.17091 & $4 \mathrm{i}$ & $\mathrm{m}$ \\
\hline $\mathrm{Co} 4$ & 0.09742 & 0.00000 & 0.01426 & $4 \mathrm{i}$ & $\mathrm{m}$ \\
\hline Co2 & 0.09808 & 0.00000 & 0.37654 & $4 \mathrm{i}$ & $\mathrm{m}$ \\
\hline Al15 & 0.17695 & 0.00000 & 0.71842 & $4 i$ & $\mathbf{m}$ \\
\hline Al12 & 0.19447 & 0.00000 & 0.22725 & $4 \mathrm{i}$ & $\mathrm{m}$ \\
\hline $\mathrm{Al} 3$ & 0.25909 & 0.00000 & 0.03874 & $4 \mathrm{i}$ & $\mathrm{m}$ \\
\hline Al5 & 0.26256 & 0.00000 & 0.46521 & $4 \mathrm{i}$ & $\mathrm{m}$ \\
\hline Co3 & 0.40945 & 0.00000 & 0.01148 & $4 \mathrm{i}$ & $\mathrm{m}$ \\
\hline Al6 & 0.41360 & 0.00000 & 0.21180 & $4 \mathrm{i}$ & $\mathrm{m}$ \\
\hline $\mathrm{Al} 2$ & 0.42642 & 0.00000 & 0.41972 & $4 \mathrm{i}$ & $\mathrm{m}$ \\
\hline Al1 & 0.56605 & 0.00000 & 0.17393 & $4 \mathrm{i}$ & $\mathrm{m}$ \\
\hline Co1 & 0.58547 & 0.00000 & 0.38244 & $4 \mathrm{i}$ & $\mathrm{m}$ \\
\hline Al9 & 0.00000 & 0.24950 & 0.00000 & $4 \mathrm{~g}$ & 2 \\
\hline $\mathrm{Al} 8$ & 0.00000 & 0.00000 & 0.50000 & $2 \mathrm{c}$ & $2 / \mathrm{m}$ \\
\hline
\end{tabular}




\begin{tabular}{|c|c|c|c|c|c|}
\hline \multicolumn{6}{|c|}{$o-\mathrm{Al}_{13} \mathrm{Co}_{4}\left(\text { Spage group } \mathrm{Pmn} 2{ }_{1} \text {, group number } 31\right)^{7}$} \\
\hline \multicolumn{6}{|c|}{ Lattice parameters } \\
\hline $\mathrm{a}$ & $\mathrm{b}$ & $\mathrm{c}$ & alpha & beta & gamma \\
\hline 8.15800 & 12.34200 & 14.45200 & 90.0000 & 90.0000 & 90.0000 \\
\hline \multicolumn{6}{|c|}{ Structure parameters (x,y,z, Wyckoff number and symmetry) } \\
\hline $\mathrm{Al} 25$ & 0.22440 & 0.29460 & 0.73520 & $4 \mathrm{~b}$ & 1 \\
\hline Co4 & 0.00000 & 0.77200 & 0.31670 & $2 \mathrm{a}$ & $\mathrm{m}$ \\
\hline Al16 & 0.00000 & 0.10470 & 0.23800 & $2 \mathbf{a}$ & $\mathbf{m}$ \\
\hline Al14 & 0.00000 & 0.59860 & 0.21490 & $2 \mathrm{a}$ & $\mathrm{m}$ \\
\hline Al17 & 0.00000 & 0.41790 & 0.58810 & $2 a$ & $\mathbf{m}$ \\
\hline Al6 & 0.00000 & 0.81130 & 0.15640 & $2 \mathrm{a}$ & $\mathrm{m}$ \\
\hline Co9 & 0.22570 & 0.90990 & 0.73460 & $4 \mathrm{~b}$ & 1 \\
\hline $\mathrm{Al} 22$ & 0.22510 & 0.98100 & 0.09350 & $4 \mathrm{~b}$ & 1 \\
\hline $\mathrm{Al} 4$ & 0.00000 & 0.90850 & 0.44310 & $2 \mathrm{a}$ & $\mathrm{m}$ \\
\hline $\mathrm{Al} 24$ & 0.22590 & 0.58850 & 0.54220 & $4 \mathrm{~b}$ & 1 \\
\hline Al19 & 0.21380 & 0.90200 & 0.28310 & $4 \mathrm{~b}$ & 1 \\
\hline Co3 & 0.00000 & 0.19770 & 0.82500 & $2 \mathrm{a}$ & $\mathrm{m}$ \\
\hline $\mathrm{Al} 7$ & 0.00000 & 0.80920 & 0.83600 & $2 \mathrm{a}$ & $\mathrm{m}$ \\
\hline $\mathrm{Al} 3$ & 0.00000 & 0.90530 & 0.62260 & $2 \mathrm{a}$ & $\mathrm{m}$ \\
\hline $\mathrm{Co} 2$ & 0.00000 & 0.09010 & 0.51140 & $2 \mathrm{a}$ & $\mathrm{m}$ \\
\hline Co1 & 0.00000 & 0.89780 & 0.00000 & $2 \mathrm{a}$ & $\mathrm{m}$ \\
\hline $\mathrm{Al} 18$ & 0.21350 & 0.21380 & 0.09960 & $4 \mathrm{~b}$ & 1 \\
\hline Co5 & 0.00000 & 0.59860 & 0.82480 & $2 \mathrm{a}$ & $\mathrm{m}$ \\
\hline Al15 & 0.00000 & 0.71110 & 0.96680 & $2 \mathrm{a}$ & $\mathrm{m}$ \\
\hline Al9 & 0.00000 & 0.40700 & 0.85200 & $2 \mathrm{a}$ & $\mathrm{m}$ \\
\hline $\mathrm{Co} 7$ & 0.00000 & 0.73090 & 0.51800 & $2 \mathrm{a}$ & $\mathrm{m}$ \\
\hline $\mathrm{Al} 26$ & 0.22910 & 0.42200 & 0.42520 & $4 \mathrm{~b}$ & 1 \\
\hline $\mathrm{Al} 21$ & 0.25340 & 0.25500 & 0.91720 & $4 \mathrm{~b}$ & 1 \\
\hline Al13 & 0.00000 & 0.52710 & 0.00540 & $2 \mathrm{a}$ & $\mathrm{m}$ \\
\hline Al10 & 0.00000 & 0.40100 & 0.14910 & $2 \mathrm{a}$ & $\mathrm{m}$ \\
\hline $\mathrm{Al} 20$ & 0.24010 & 0.08290 & 0.40880 & $4 \mathrm{~b}$ & 1 \\
\hline Al1 & 0.00000 & 0.99450 & 0.81510 & $2 \mathrm{a}$ & $\mathrm{m}$ \\
\hline $\mathrm{A} 12$ & 0.00000 & 0.09140 & 0.95690 & $2 \mathrm{a}$ & $\mathrm{m}$ \\
\hline $\mathrm{A} 15$ & 0.00000 & 0.13940 & 0.67280 & $2 a$ & $\mathrm{~m}$ \\
\hline Co8 & 0.00000 & 0.28770 & 0.00760 & $2 \mathrm{a}$ & $\mathrm{m}$ \\
\hline Al11 & 0.00000 & 0.68370 & 0.67490 & $2 \mathrm{a}$ & $\mathrm{m}$ \\
\hline $\mathrm{Al} 27$ & 0.21330 & 0.51740 & 0.73380 & $4 \mathrm{~b}$ & 1 \\
\hline Al12 & 0.00000 & 0.59000 & 0.39600 & $2 \mathrm{a}$ & $\mathrm{m}$ \\
\hline Co6 & 0.00000 & 0.41190 & 0.31370 & $2 \mathrm{a}$ & $\mathrm{m}$ \\
\hline $\mathrm{Al} 28$ & 0.23190 & 0.27630 & 0.28490 & $4 \mathrm{~b}$ & 1 \\
\hline Co10 & 0.21810 & 0.59690 & 0.09840 & $4 \mathrm{~b}$ & 1 \\
\hline $\mathrm{Al} 8$ & 0.00000 & 0.25200 & 0.41400 & $2 a$ & $\mathrm{~m}$ \\
\hline $\mathrm{Al} 23$ & 0.22140 & 0.22290 & 0.55000 & $4 \mathrm{~b}$ & 1 \\
\hline
\end{tabular}




\section{S4 - LEED-AFM-STM}

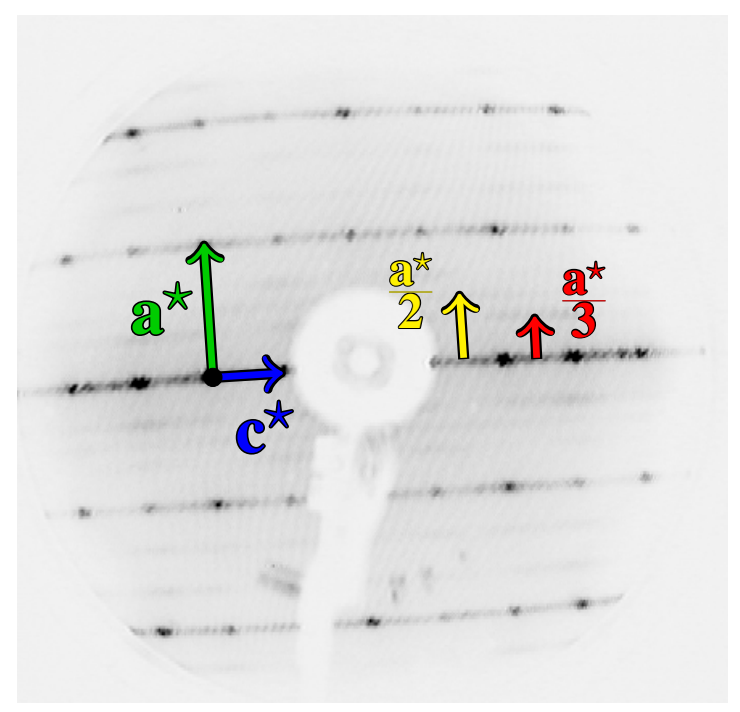

(a) LEED pattern

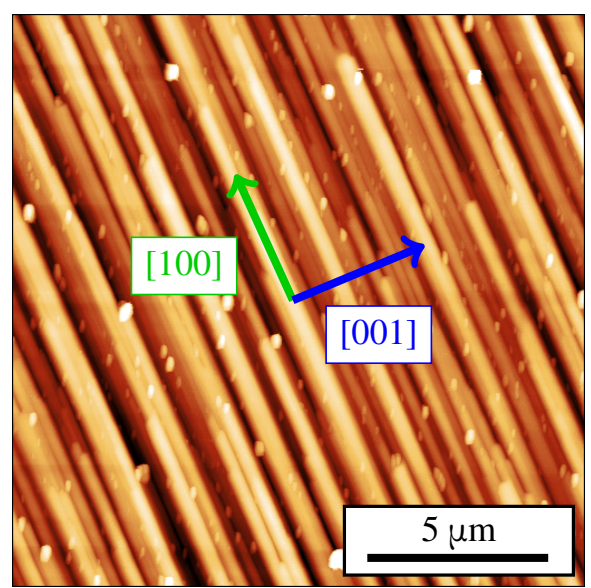

(b) AFM image

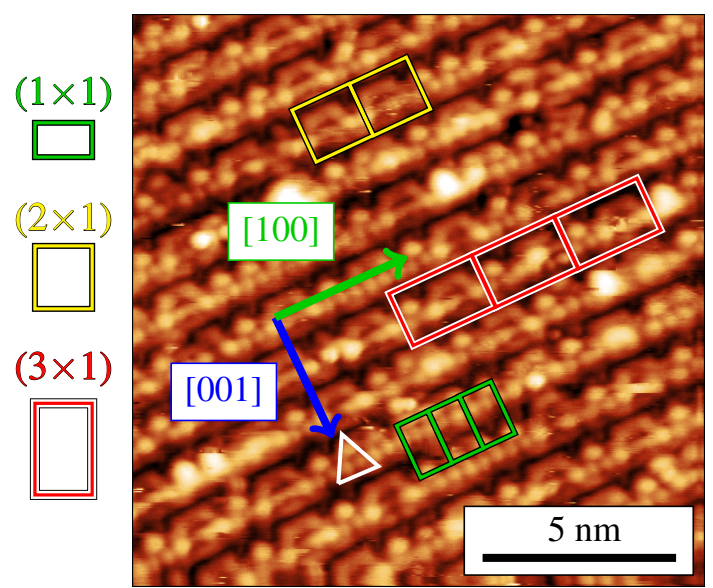

(c) STM image

Figure S6: (a) LEED pattern measured at $30 \mathrm{eV}$. Diffuse scattering resembling a $(2 \times 1)$ and a $(3 \times 1)$ surface reconstructions are shown in yellow and red arrows, respectively. (b) AFM image of $o-\mathrm{Al}_{13} \mathrm{Co}_{4}(010)\left(15 \times 15 \mu \mathrm{m}^{2}\right)$ showing a columnar and faceted structure. (c) STM image of a flat terrace at the $o-\mathrm{Al}_{13} \mathrm{Co}_{4}(010)$ surface $\left(15 \times 15 \mathrm{~nm}^{2}\right)$ at $\mathrm{V}_{\mathrm{b}}$ $=0.6 \mathrm{~V}$. The $(1 \times 1),(2 \times 1)$ and $(3 \times 1)$ cells are drawn in green, yellow and red, respectively. A triangular motif is highlighted in white. 


\section{$\mathrm{S} 5-o-\mathrm{Al}_{13} \mathrm{Co}_{4}(010)$ and $m-\mathrm{Al}_{13} \mathrm{Co}_{4}(\overline{2} 01)$ surface models}

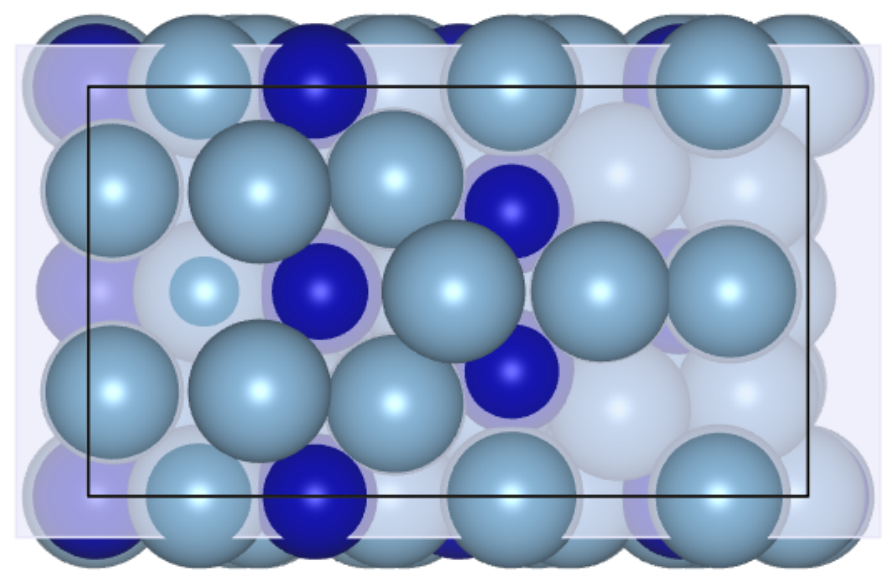

Figure S7: Surface structure of model $\mathrm{O}_{0} . \mathrm{Al}$ and Co atoms are drawn in light blue and dark blue, respectively.

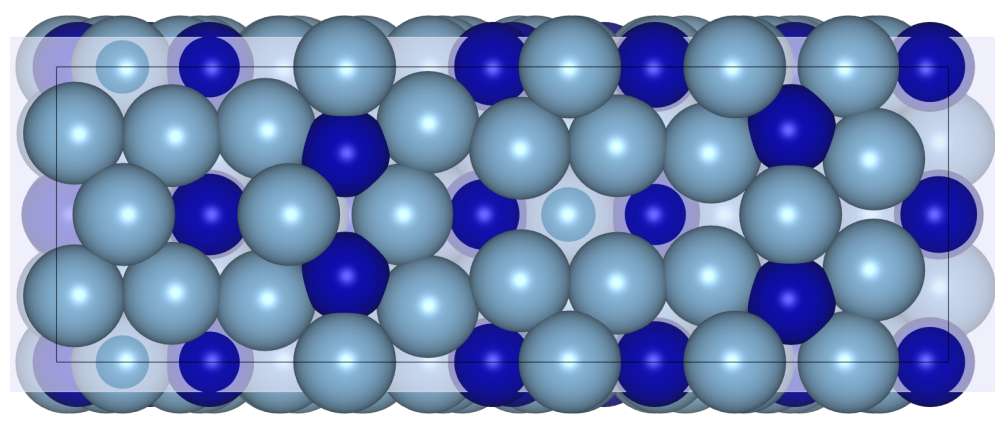

Figure S8: Surface structure of model $\mathrm{M}_{3.15}$. Al and Co atoms are drawn in light blue and dark blue, respectively. 


\section{References}

(1) Saito, K.; Sugiyama, K.; Hiraga, K. $\mathrm{Al}_{13} \mathrm{M}_{4}$-type Structures and Atomic Models of their Twins Mater. Sci. Eng. A 2000, 294-296, 279-282.

(2) Feuerbacher, M.; Heggen, M. On the Concept of Metadislocations in Complex Metallic Alloys Philos. Mag. 2006, 86, 935-944.

(3) Heggen, M.; Houben, L.; Feuerbacher, M. Metadislocations in the Structurally Complex Orthorhombic Alloy $\mathrm{Al}_{13} \mathrm{Co}_{4}$ Philos. Mag. 2008, 88, 2333-2338.

(4) Heggen, M.; Houben, L.; Feuerbacher, M. Plastic-Deformation Mechanism in Complex Solids Nat. Mater. 2010, 9, 332-336.

(5) Heidelmann, M.; Heggen, M.; Dwyer, C.; Feuerbacher, M. Comprehensive Model of Metadislocation Movement in $\mathrm{Al}_{13} \mathrm{Co}_{4}$ Scr. Mater. 2015, 98 .

(6) Hudd, R.; Taylor, W. The Structure of $\mathrm{Co}_{4} \mathrm{Al}_{13}$ Acta Cryst. A 1962, 15, 441.

(7) Grin, J.; Burkhardt, U.; Ellner, M.; Peters, K. Crystal Structure of Orthorhombic $\mathrm{Co}_{4} \mathrm{Al}_{13} J$. Alloys Compd. 1994, 206, 243-247. 